FY 98 Final Report

\title{
Initial Interfacial Chemical \\ Control for Enhancement of \\ Composite Material Strength
}

Kevin L. Simmons

Glen E. Fryxell

William D. Samuels

Roger D. Voise

Kentin L. Alford*

September 1999

Prepared for

Systems Readiness Center at U.S. Army, TACOM-ARDEC, Picatinny Arsenal, New Jersey 07806-5000

Pacific Northwest National Laboratory

Operated by Battelle for the

U.S. Department of Energy

*Associated Western Universities

Richland, Washington 



\section{DISCLAIMER}

This report was prepared as an account of work sponsored by an agency of the United States Government. Neither the United States Government nor any agency thereof, nor any of their employees, make any warranty, express or implied, or assumes any legal liability or responsibility for the accuracy, completeness, or usefulness of any information, apparatus, product, or process disclosed, or represents that its use would not infringe privately owned rights. Reference herein to any specific commercial product, process, or service by trade name, trademark, manufacturer, or otherwise does not necessarily constitute or imply its endorsement, recommendation, or favoring by the United States Government or any agency thereof. The views and opinions of authors expressed herein do not necessarily state or reflect those of the United States Government or any agency thereof. 


\section{DISCLAIMER}

Portions of this document may be illegible in electronic image products. Images are produced from the best available original document. 


\section{Summary}

The U.S. Army Armament Research Development \& Engineering Center (ARDEC) sponsored this research project to support the development of new self-assembled monolayer fiber coatings. These coatings can greatly increase the bond strength between the fiber and the resin matrix of a composite material. Composite ammunition components molded from such materials will exhibit higher strength than current materials, and will provide a major improvement in the performance of composites in military applications. Use of composite materials in military applications is desirable because of the lighter weight of the materials and their high strengths.

The FY97 project investigated initial interfacial chemical control for enhancement of composite material strength. The core of the project was to modify the covalent interface of glass fibers (or other reinforcing fibers) to induce strong, uniform, defect-free adhesion between the fibers' surfaces and the polymer matrix. Installing a self-assembled monolayer tailored to the specific matrix resin accomplished this. Simply, the self-assembled monolayer modifies the fiber to make it appear to have the same chemical composition as the resin matrix. The self-assembled monolayer creates a receptive, hydrophobic interface that the thermoset resin (or polymer precursors) would wet more effectively, leading to a higher contact surface area and more efficient adhesion.

The FY97 work phase demonstrated that it is possible to increase the adhesive strength, as well as increase the heat deflection temperature through the use of self-assembled monolayers.

Work in FY98 focused on glass fiber composites and their bulk properties. The bulk properties testing of composite laminates were made from different glass fiber surface treatments that were done on tensile, flexural, and short-beam shear specimens. The SAM treatments on glass fibers have demonstrated an improved affect in the overall composite bulk properties. The matrix materials for a thermoset system can be chemically bonded to the glass fiber surface. The chemical bond takes place through the curing mechanism called crosslinking. The epoxy resin can be crosslinked to the surface of the chemically prepared surface or epoxide groups on the glass fiber surfaces can be cross-linked with the curing agent that has been mixed in with the epoxy resin. The research included applying various SAM treatments to the glass fiber mats and compared them to a non-surface treated glass fiber system and a commercially available glass fiber. Once the resin system is crosslinked and cured, the SAM affects the adhesion to the surface of the glass fiber and as well as the modulus in the interphase region. The different types of SAMs can control the modulus of the material in the interphase area. The tensile test shows the effect that the SAMs have on the strength of the material. The 3-('3,'4-epoxycyclohexyloxly)-3-propyltrimethoxysilane SAM showed the highest tensile strength as well as the highest short-beam shear.

The other SAMs show some improvements but the properties were anticipated to be different. The testing data for the other SAMs demonstrated that by controlling the chemical interface with the SAM system, the properties can be tailored to what is desired. For instance, if a toughened system is desired, a lower modulus interface can be applied. 
Using the proof-of-principle that SAMs can improve the properties of polymeric glass fiber composites, the use of SAMs on polymeric thermoplastics on carbon fiber was investigated. The initial work examined what was available to attach to on the surface of the carbon fiber and if additional oxidation treatments were going to be needed. Some gentle oxidation treatments were done and SEMs were completed. The work in FY99 will complete the proof-of-principle that the carbon fibers can accept SAM treated surfaces and improve the strength of thermoplastic carbon fiber composite materials. 


\section{Contents}

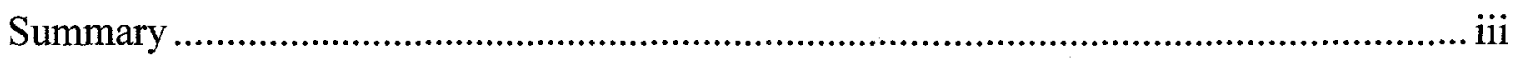

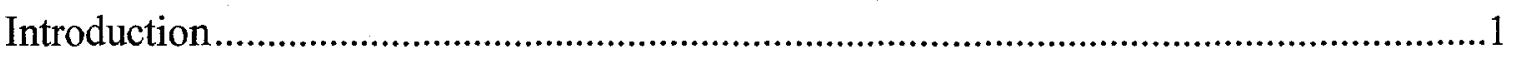

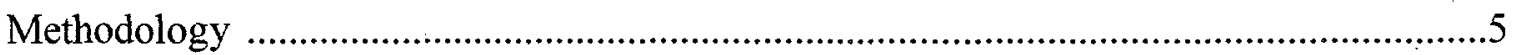

\section{Thermoset Phase}

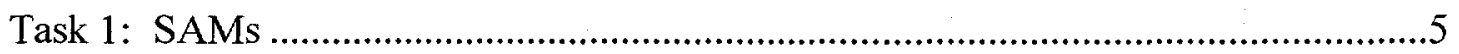

Research for Optimum SAMs for AS-4 Fibers and PEI .............................................

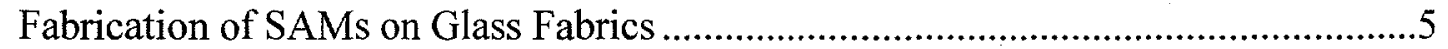

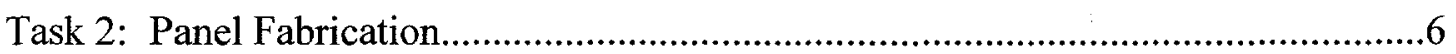

Task 3: Test Specimen Part Fabrication ..................................................................

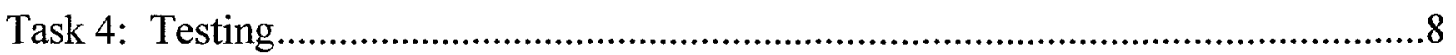

Flexural Modulus Measurements......................................................................

Short Beam Shear Testing ................................................................................

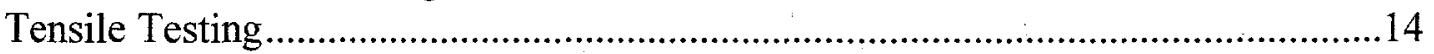

\section{Thermoplastic Phase}

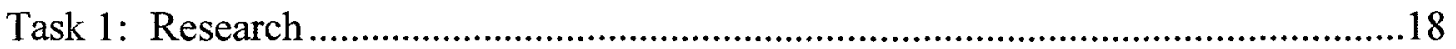

Research for Optimum SAMs for AS-4 Fibers and PEI ...........................................18

Research on Coating Fibers with PEI ……...........................................................18

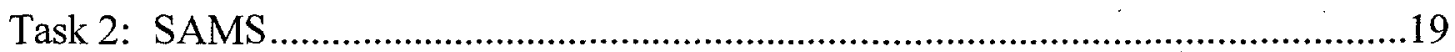

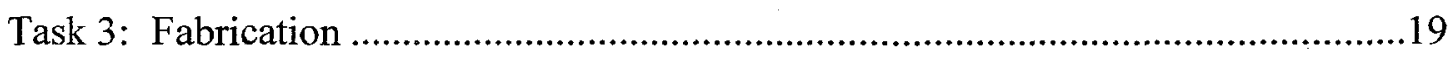

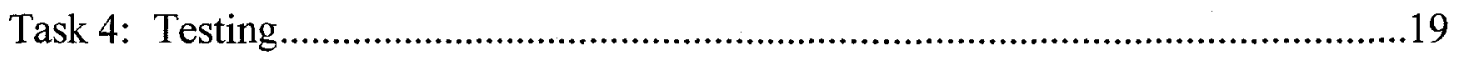

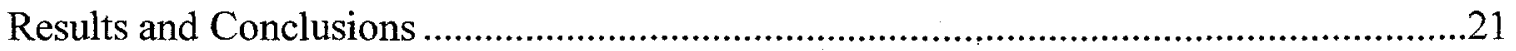




\section{Figures}

1 Silica surface derivatized with reactive ends of a SAM molecule, which reacts and crosslinks with thermoset materials

2 Interaction of the epoxy resin with the untreated vs. treated surfaces ............................

3 Interaction of cured epoxy matrix with untreated vs. treated surfaces ...........................

4 Flexural modulus (average values) ........................................................................

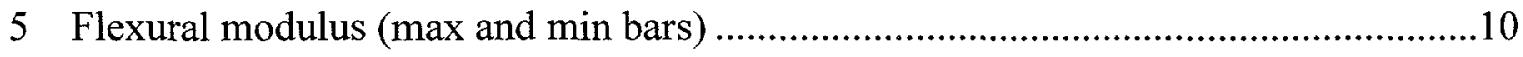

6 Flexural modulus (+/- st deviation error bars) ……................................................11

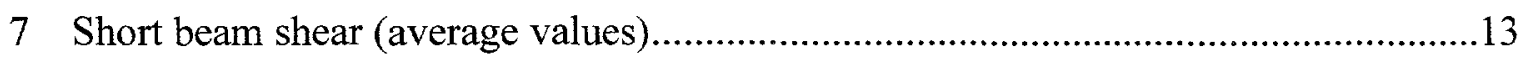

8 Short beam shear (+/- st deviation error bars)........................................................13

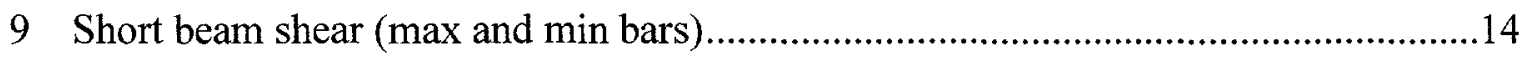

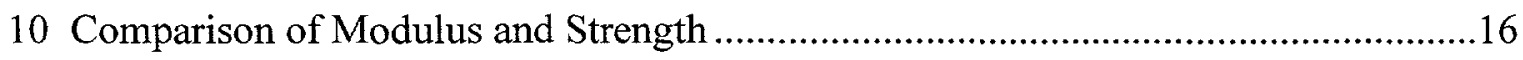

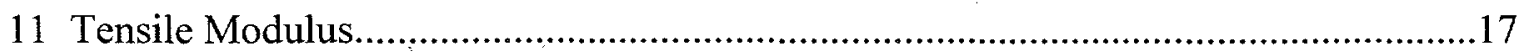

12 Scanning Electron Microscopy of ECH SAM Tensile Fracture ....................................18

13 Load transfer stress distributions in a single fiber embedded in a matrix Material and subjected to an axial load

\section{Tables}

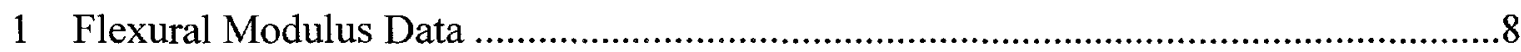

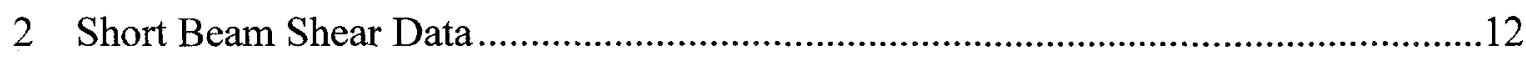

3 Tensile Test Data (1/4" Notched Specimens) ………….............................................14 


\section{Introduction}

The U.S. Army Armament Research Development \& Engineering Center (ARDEC) sponsored this research project to support the development of new self-assembled monolayer fiber coatings. These coatings can greatly increase the bond strength between the fiber and the resin matrix of a composite material. Composite munitions components molded from such materials will exhibit higher strength than current materials, and will provide a major improvement in the performance of composites in military applications. Use of composite materials in military applications is desirable because of the lighter weight of the materials and their high strength.

The core of the FY97 project was to modify the covalent interface of glass fibers or glass substrates (or other reinforcing fibers) to induce strong, uniform, defect-free adhesion between the fiber's surface and the polymer matrix, thus increasing the strength or toughness of composite materials. Installation of 10 self-assembled monolayers (SAMs) were tailored to the specific epoxy matrix resin used. The 10 SAMs used were 3-amimopropyltrimethoxy-silane (APS); octadecyltrichloroysilane (OTS); trifluoroethyl ester of 11-trichlorosilyl undecanoic acid (TFEE); glycidyl [(2-epoxypropyloxy)-3-propyltrimethoxysilane]; tetradecyltrichlorosilane(TTS); 3('3,'4-epoxycyclohexyloxly)-3-propyltrimethoxysilane (ECH); (2-aminoethyl) aminopropyltrimenthoxysilane) (AEAP); diethylenetriaminetrimethoxysilane (DETA); and 3-isocyanatopropyltrimethpoxysilane (NCO). Fiber, diatomaceous earth, and glass slides were modified to provide a surface that looks to the resin matrix as if it had the same chemical composition as the matrix resin.

The SAMs created a receptive, hydrophobic interface that thermoset resins (or polymer precursors) wet effectively, leading to high contact surface area and efficient adhesion. The surface energy of glass was measured to the thermoset resin before and after surface modifications and the result was surprising, but explainable.

One method for characterizing the chemical behavior of a surface is to measure its wettability. This can be done using a solvent such as water, $\mathrm{pH}$ buffers or non-volatile organic solvents, as a way of gauging the different components (acid/base properties, permanent dipole moment, polarizability) of the overall interfacial wettability. The most common of these measurements is the water contact angle measurement, in which a droplet of water is placed on the surface and the angle formed between the edge of the droplet and the surface is measured precisely. A hydrophilic surface will wet very nicely with water and the droplet will "wick out" across the surface, resulting in a very low contact angle ( $<10$ degrees). A hydrophobic surface will cause the droplet to "bead up", and the contact angle will be high ( $>90$ degrees).

While these measurements are useful to the surface scientist, they don't directly address our question as to how well these SAM-coated surfaces wet with an epoxy resin. This epoxy wettability has a direct influence on the contact area, and hence the interfacial adhesion, between the two phases of the resulting composite. Thus, we chose to measure the contact angle formed by the epoxy resin on our monolayer-coated substrates. 
The results of these water contact angle measurements for monolayer coated substrates are summarized as follows:

$\begin{array}{lr}\text { NCO } & 22^{\circ} \\ \text { APS } & 16^{\circ} \\ \text { ECH } & 24^{\circ} \\ \text { Gly } & 16^{\circ} \\ \text { None } & 6^{\circ}\end{array}$

Note that the native glass slides is more wettable (by the epoxy mix) than our coated surfaces. Therefore, we can safely conclude that whatever strength enhancement we observe in the lapshear tests is in fact due to covalent attachment between the two phases, and not simply due to increased interfacial contact. Research conducted in FY97 served to narrow down the wide range of possibilities with SAMs to the current four listed above.

The complete and uniform coverage of the SAM formation spreads the adhesion between the fiber and the matrix evenly over a larger area of the glass fiber relative to an uncoated fiber. This will reduce composite failure due to fiber/matrix interfacial shear. This application should enhance high fatigue components or in cases where severe environments could affect the physical properties of the composite. Using SAM coatings to control the physical properties of the interphase region, the tailored monolayer can improve composite strength or toughness. A rigid interphase will enhance composite strength and a flexible interphase will promote composite toughness.

The testing performed during FY97 determined what kind of increases in properties could be attained in the SAM composites. Unanticipated problems with testing and a search for reliable test procedures required most of the effort. We started with high surface area diatomaceous earth (Celite $\left.{ }^{\circledR}\right)$ mixed in epoxy for Dynamic Mechanical Analysis (DMA). This test showed us what kind of changes in storage modulus and glass transition temperatures. Increases in storage modulus shows an increase in bond strength and increases in glass transition temperature shows the change in the degree of cross-linking due to surface chemistry modifications and high surface area. The ability of the Celite $\AA$ material, with SAM coatings, to mix into the epoxy helped us determine which SAMs were more receptive to the epoxy matrix. This allowed us to reduce the number of SAMs to four of the most promising. We also tried single embedded fiber tensile specimens, microbead shear testing, and glass slide lapshear testing. The lapshear testing held the most promise in FY97 and we focused our efforts in that area. The adhesions were strong enough that special fixturing and thick slide specimens were in need of being fabricated and a significant reduction in adhesive area was needed. The results were that the SAMs outperformed a direct coating of silane coupling agent to the surface.

Based on these results, continued testing done during FY98 was accomplished in two phases: a thermoset phase and a thermoplastic phase. The thermoset phase was at the core of FY98's research with composite samples being made up of glass and epoxy resin systems. The glass comparisons were done on three different bases. The material was an E-glass fabric from Advanced Composites, Eureka Springs, Arizona. The three different comparisons were done with 1) an as-received, unsized plain-weave glass fabric of $8.95 \mathrm{oz} / \mathrm{yd}$ material; 2) an as-received, 
commercial glass finished fabric from the same manufacturer using the same weave and weight; and 3) an unsized glass fabric for coating the four different SAM materials. Composite panels were made from these materials and cut into specimens for testing. The testing consisted of flexural modulus and strength, short-beam shear testing, and tensile strength and modulus. Other testing consisted of the microbead test, which was difficult and gave inconsistent results, and the fragmentation techniques, which also was difficult to perform and to interpret results from inconsistent data as well. 



\section{Methodology}

The FY98 project consisted of two phases-the thermoset phase and the thermoplastic phase- to be accomplished within four tasks each. The thermoset phase encompassed fabrication of SAMs on glass fabrics, fabricating panels for test specimens, and a testing task. The thermoplastic phases encompassed researching the possibility of using SAMs on carbon fibers with polyetherimide (PEI), and developing a strategy for apply SAMs to the surface and test procedures.

\section{Thermoset Phase}

\section{Task 1: SAMs}

\section{Research for Optimum SAMs for AS-4 Fibers and PEI}

A search was conducted for optimizing available oxygen-containing molecules on carbon fiber surfaces. The greater the number of surface oxygens (i.e., hydroxyls) the more complete the SAM coverage. The available literature indicated that to enhance the surface oxygen content, a compromise needed to be accepted for a reduction in fiber strength. In essence, the current industrial oxidation techniques are non-selective. Mild oxidation techniques were examined and tested on carbon fibers. Examination of the increase in surface oxygen content was not significant.

The SAM molecules that will be attached to the carbon fiber surfaces will be the same as those molecules that were applied to the glass surfaces, with the addition of a long chain $(\mathrm{C}>16)$ hydrocarbon SAM. This effort will be considered in FY99 research efforts.

\section{Fabrication of SAMs on Glass Fabrics}

Formation of SAMs on fiberglass cloth follows a general procedure. Fiberglass cloth $(15 \mathrm{~cm} \mathrm{x}$ $250 \mathrm{~cm}$; CS-724 grade; Style 7781; Advanced Composites) was carefully accordion folded onto the internal pin assembly of the reaction vessel. The loaded rack was then submerged in 2-propanol and stirred magnetically for 20-30 min to remove superficial impurities from the surface of the glass weave. After washing, the rack was removed and the 2-propanol was decanted from the vessel. The rack was replaced and the vessel purged with a vigorous flow of dry nitrogen for at least $2 \mathrm{~h}$ to remove all traces of solvent. The nitrogen line was then routed through a water bubbler, so that the resulting nitrogen stream would be saturated with water vapor. This $100 \%$ relative humidity nitrogen stream was then routed through the reaction vessel for $1 \mathrm{~h}$ to ensure that the clean glass surface was adequately (and uniformly) hydrated (interfacial water is critical to the success of good monolayer formation). At this point, the top of the apparatus was removed and approximately $6 \mathrm{~L}$ of toluene added and the top replaced. The headspace was flushed with dry nitrogen for $15 \mathrm{~min}$, then $25 \mathrm{~mL}$ of the appropriate silane (NCO, GLY, ECH, etc.) was added via syringe through the septum in the vessel lid. The vessel was placed on a hot plate/stirrer and stirring and heating initiated. The reaction mixture was equilibrated at approximately $70^{\circ} \mathrm{C}$ for $18 \mathrm{~h}$, then allowed to cool to ambient temperature. Once cool, the reaction melange was decanted off and the vessel refilled with 2-propanol and the coated glass fiber was once again washed for 20-30 min in 2-propanol. When the washing was completed, the 2-propanol was decanted off and the glass cloth was once again dried under a stream of dry nitrogen for $1 \mathrm{~h}$. 
Figure 1 shows how the silica surface is derivatized with reactive ends of a SAM molecule that reacts and crosslinks with the thermoset materials.

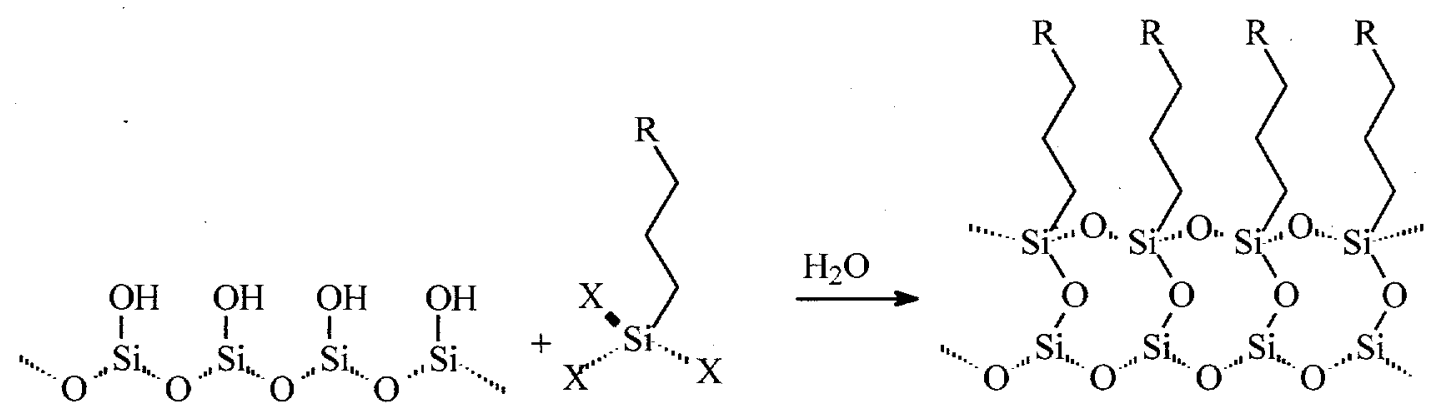

\section{Silica Surface}

\section{Derivatized Surface}

Figure 1. Silica surface derivatized with reactive ends of a SAM molecule, which reacts and crosslinks with thermoset materials

\section{Task 2: Panel Fabrication}

Several sizes of panels were initial considered before selecting the two used for this task-one that was $1.6 \mathrm{~mm}$ thick and the other $4.0 \mathrm{~mm}$ thick. The pieces of E-glass were initially cut slightly over size so that the fiber strands could be pealed down until the sides were parallel and to a dimension of $15.2 \mathrm{~cm} \times 15.2 \mathrm{~cm}$. The glass was cut from long strips and one edge was. marked to ensure that the fiber orientation was the same when the pieces were laid up.

Many trials were performed to determine the number of layers needed to achieve the 60 percent glass by weight. Six layers of E-glass were required to achieve 60 percent glass by weight in the $1.6-\mathrm{mm}$ specimen. Fifteen layers were required to obtain the 60 percent glass by weight in the $4.0-\mathrm{mm}$ specimens. In the early trials, the glass was weighed before the lay-up process and the complete composite was weighed afterward to confirm that the desired percent glass was being obtained. In addition to meeting the 60 percent by weight requirement, it was also important to ensure that the fibers were not being compressed too tightly in the mold.

The lay-up process consisted of mixing the REFCOA epoxy and DETA curing agent at the calculated proportions and placing it in a vacuum to degas. First, a small amount of epoxy was brushed on the bottom of the mold, followed by the first layer of glass. A paintbrush was used to wet each piece of glass and blot the epoxy. After the desired number of layers was achieved, the top of the mold was replaced and the whole mold was placed in a heated press and left for $1 \mathrm{~h}$ at $100{ }^{\circ} \mathrm{C}$ with an internal pressure of $38 \mathrm{kPa}$. Figure 2 shows the difference of the chemical interaction with the glass surface with and without SAM treatment. Figure 3 shows the interaction of the epoxy in the cured state and how the epoxy chemically mixes and cures to the SAM surface. 
Matrix Epoxide

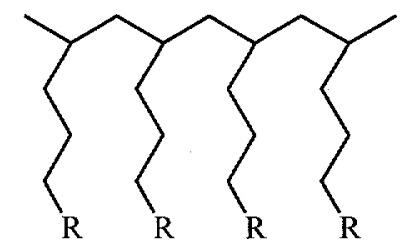

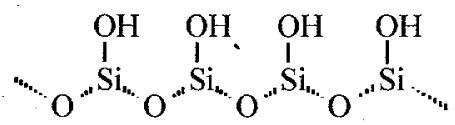

Untreated Silica Surface

\section{Matrix Epoxide}
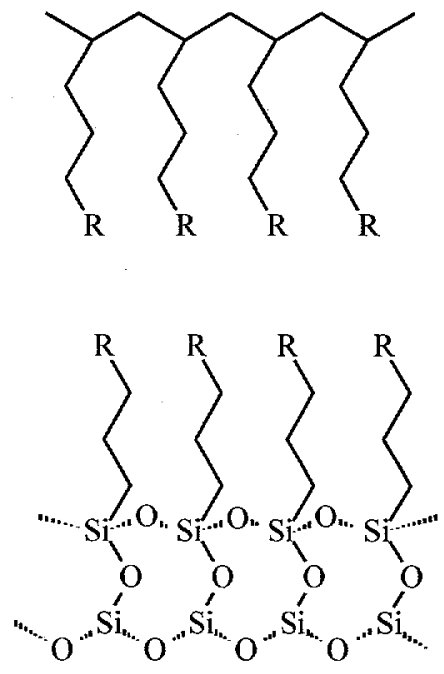

SAM Treated Silica Surface

Figure 2. Interaction of the epoxy resin with the untreated vs. treated surfaces

Matrix Epoxide<smiles>[R]CCCC(C)CC(CCC[R])CC(CCC[R])CC(C)CCC[R]</smiles><smiles>CO[SiH](O)O[SiH](O)O[SiH](O)O[SiH](C)O</smiles>

Untreated Silica Surface
Matrix Epoxide

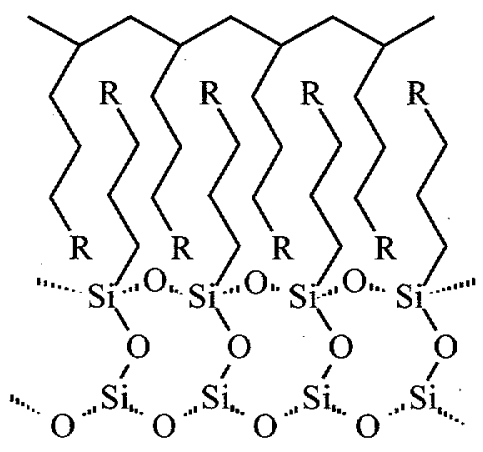

SAM Treated Silica Surface

Figure 3. Interaction of cured epoxy matrix with untreated vs. treated surfaces

\section{Task 3: Test Specimen Part Fabrication}

The tensile test specimens were cut from the $15.2-\mathrm{cm} \times 15.2-\mathrm{cm} \times 1.6-\mathrm{mm}$ panels. The specimens were cut so that the unidirectional fiber lay in the longitudinal direction. Originally, the specimens were cut in 25.4-mm widths, to duplicate the standards used in the ASTM D3039 testing method. Tabs $(2.54 \mathrm{~cm} \times 3.81 \mathrm{~cm} \times 4.0 \mathrm{~mm})$ were bonded to the specimens as prescribed in the test method. However, when attempting to test them, the tabs would detach before the specimens could fail. The specimens were cut in half to approximately $1.27 \mathrm{~cm}$ wide and tested. Again the tabs detached from the specimens. A $6.35-\mathrm{mm}$ radius was cut into the specimen on 
both sides at the mid-point of the specimen. This created a smaller cross-sectional area (roughly half) and allowed the sample to fail before the tabs detached.

The samples for the flex modulus test were cut out of the $4.0-\mathrm{mm}$-thick panels to a dimension of $1.27 \mathrm{~cm} \times 3.18 \mathrm{~cm}$ long. ASTM 790 was used as guidance in the sample prep for flexural modulus and strength. Again the direction of the fibers were in the longitudinal direction for both the flex modulus samples and the short beam shear samples. The short beam shear samples were also cut out of the 4.0 -mm-thick panels, and their dimensions were $4.0 \mathrm{~mm}$ wide $\times 2.54 \mathrm{~cm}$ long.

\section{Task 4: Testing}

The flexural modulus and short beam shear strength of sixty composite samples were measured. The results are summarized in the following spreadsheets and plots.

\section{Flexural Modulus Measurements}

The flexural testing is the simplest of the tests to perform. In general, it is considered an intrinsic property and is also inexpensive to run. However, flexural testing does not provide the basic material properties. This is due to the fact that when a beam is under load, it will have compression on one side, tension on the other, and pure shear in the neutral axis of the specimen. The flexural measurement gives a combination of these three properties. Thus, depending on the values of each of the three components in a composite material, any one of the values may actually be measured. Usually the shear component is kept small by making the test specimen relatively long compared to the thickness. The ASTM 790 standard gives guidance to the sample size and test parameters.

The flexural moduli of the composite materials were measured on a Rheometrics RMS-605. The samples were placed in a three-point bend tool with knife-edges. A room temperature (approximately $22^{\circ} \mathrm{C}$ ) frequency sweep was used to measure the flexural modulus of each sample. The frequency was varied from $0.693-100 \mathrm{~Hz}$ in two different tests, with the frequency increasing in the first test and decreasing in the second test. The values reported in Table 1 are for $1 \mathrm{~Hz}$. The modulus was approximately constant over this frequency range and the forward and reverse frequency sweeps gave excellent agreement. The average readings for each set are plotted in Figures 4 to 6 .

\begin{tabular}{|c|c|c|c|c|}
\hline \multicolumn{5}{|c|}{ Table 1: Flexural Modulus Data } \\
\hline Sample ID & Width (in) & Thickness (in) & $\begin{array}{l}\text { Flexural Modulus } \\
(\text { dyn/cm } 2)\end{array}$ & $\begin{array}{l}\text { Flexural Modulus } \\
\text { (psi) }\end{array}$ \\
\hline FM9-01 & 0.5035 & 0.1555 & $2.6254 \mathrm{E}+10$ & $3.8078 \mathrm{E}+05$ \\
\hline FM9-02 & 0.5015 & 0.1550 & $2.7565 \mathrm{E}+10$ & $3.9980 \mathrm{E}+05$ \\
\hline FM0-03 & 0.5015 & 0.1560 & $2.6996 \mathrm{E}+10$ & $3.9155 \mathrm{E}+05$ \\
\hline FM9-04 & 0.5040 & 0.1550 & $2.4022 \mathrm{E}+10$ & $3.4841 \mathrm{E}+05$ \\
\hline \multirow{3}{*}{ FM9-05 } & 0.5035 & 0.1560 & $2.6609 \mathrm{E}+10$ & $3.8593 \mathrm{E}+05$ \\
\hline & & Average & $2.6289 \mathrm{E}+10$ & $3.8129 \mathrm{E}+05$ \\
\hline & & St Deviation & $1.3575 \mathrm{E}+09$ & $1.9689 \mathrm{E}+04$ \\
\hline
\end{tabular}




\begin{tabular}{|c|c|c|c|c|}
\hline \multicolumn{5}{|c|}{ Table 1: Flexural Modulus Data (continued) } \\
\hline FM10-01 & 0.5020 & 0.1550 & $2.0511 \mathrm{E}+10$ & $2.9749 \mathrm{E}+05$ \\
\hline FM10-02 & 0.5020 & 0.1545 & $2.0805 \mathrm{E}+10$ & $3.0175 \mathrm{E}+05$ \\
\hline FM10-03 & 0.5015 & 0.1545 & $2.4031 \mathrm{E}+10$ & $3.4854 \mathrm{E}+05$ \\
\hline FM10-04 & 0.5010 & 0.1535 & $2.0928 \mathrm{E}+10$ & $3.0354 \mathrm{E}+05$ \\
\hline \multirow[t]{3}{*}{ FM10-05 } & 0.5040 & 0.1550 & $2.1663 \mathrm{E}+10$ & $3.1420 \mathrm{E}+05$ \\
\hline & \multicolumn{2}{|r|}{ Average } & $2.1588 \mathrm{E}+10$ & $3.1310 \mathrm{E}+05$ \\
\hline & \multicolumn{2}{|r|}{ St Deviation } & $1.4303 \mathrm{E}+09$ & $2.0744 \mathrm{E}+04$ \\
\hline FM14-01 & 0.5025 & 0.1560 & $2.6536 \mathrm{E}+10$ & $3.8487 \mathrm{E}+05$ \\
\hline FM14-02 & 0.5025 & 0.1560 & $2.4751 \mathrm{E}+10$ & $3.5898 \mathrm{E}+05$ \\
\hline FM14-03 & 0.5030 & 0.1560 & $2.3808 \mathrm{E}+10$ & $3.4531 \mathrm{E}+05$ \\
\hline FM14-04 & 0.5030 & 0.1560 & $2.2999 \mathrm{E}+10$ & $3.3357 \mathrm{E}+05$ \\
\hline \multirow[t]{3}{*}{ FM14-05 } & 0.5010 & 0.1560 & $2.4615 \mathrm{E}+10$ & $3.5701 \mathrm{E}+05$ \\
\hline & \multicolumn{2}{|r|}{ Average } & $2.4542 \mathrm{E}+10$ & $3.5595 \mathrm{E}+05$ \\
\hline & \multicolumn{2}{|r|}{ St Deviation } & $1.3176 \mathrm{E}+09$ & $1.9111 \mathrm{E}+04$ \\
\hline FM17-01 & 0.5015 & 0.1545 & $2.5477 \mathrm{E}+10$ & $3.6951 \mathrm{E}+05$ \\
\hline FM17-02 & 0.5030 & 0.1545 & $2.7150 \mathrm{E}+10$ & $3.9378 \mathrm{E}+05$ \\
\hline FM17-03 & 0.5010 & 0.1550 & $2.8810 \mathrm{E}+10$ & $4.1786 \mathrm{E}+05$ \\
\hline FM17-04 & 0.5015 & 0.1550 & $2.6566 \mathrm{E}+10$ & $3.8531 \mathrm{E}+05$ \\
\hline \multirow[t]{3}{*}{ FM17-05 } & 0.5020 & 0.1555 & $2.8663 \mathrm{E}+10$ & $4.1572 E+05$ \\
\hline & \multicolumn{2}{|r|}{ Average } & $2.7333 \mathrm{E}+10$ & $3.9644 \mathrm{E}+05$ \\
\hline & \multicolumn{2}{|r|}{ St Deviation } & $1.4157 \mathrm{E}+09$ & $2.0533 \mathrm{E}+04$ \\
\hline FM18-01 & 0.4995 & 0.1540 & $1.7161 \mathrm{E}+10$ & $2.4890 \mathrm{E}+05$ \\
\hline FM18-02 & 0.4995 & 0.1540 & $2.1430 \mathrm{E}+10$ & $3.1082 \mathrm{E}+05$ \\
\hline FM18-03 & 0.5015 & 0.1540 & $1.7510 \mathrm{E}+10$ & $2.5396 \mathrm{E}+05$ \\
\hline FM18-04 & 0.5015 & 0.1535 & $1.7779 \mathrm{E}+10$ & $2.5786 \mathrm{E}+05$ \\
\hline \multirow[t]{3}{*}{ FM18-05 } & 0.5000 & 0.1545 & $2.3212 E+10$ & $3.3666 \mathrm{E}+05$ \\
\hline & \multirow{2}{*}{\multicolumn{2}{|c|}{$\begin{array}{l}\text { Average } \\
\text { St Deviation }\end{array}$}} & $1.9418 \mathrm{E}+10$ & $2.8164 \mathrm{E} \div 05$ \\
\hline & & & $2.7324 \mathrm{E}+09$ & $3.9630 \mathrm{E}+04$ \\
\hline \multirow{7}{*}{$\begin{array}{l}\text { FM21-01 } \\
\text { FM21-02 } \\
\text { FM21-03 } \\
\text { FM21-04 } \\
\text { FM21-05 }\end{array}$} & 0.5015 & 0.1540 & $2.4609 \mathrm{E}+10$ & $3.5692 \mathrm{E}+05$ \\
\hline & 0.5005 & 0.1550 & $2.6832 \mathrm{E}+10$ & $3.8917 E+05$ \\
\hline & 0.4995 & 0.1545 & $2.4968 \mathrm{E}+10$ & $3.6213 \mathrm{E}+05$ \\
\hline & 0.5005 & 0.1540 & $2.4738 \mathrm{E}+10$ & $3.5880 \mathrm{E}+05$ \\
\hline & 0.4995 & 0.1540 & $2.5415 \mathrm{E}+10$ & $3.6861 E+05$ \\
\hline & \multirow{2}{*}{\multicolumn{2}{|c|}{$\begin{array}{l}\text { Average } \\
\text { St Deviation }\end{array}$}} & $2.5312 \mathrm{E}+10$ & $3.6713 E+05$ \\
\hline & & & $9.0319 \mathrm{E}+08$ & $1.3100 \mathrm{E}+04$ \\
\hline
\end{tabular}




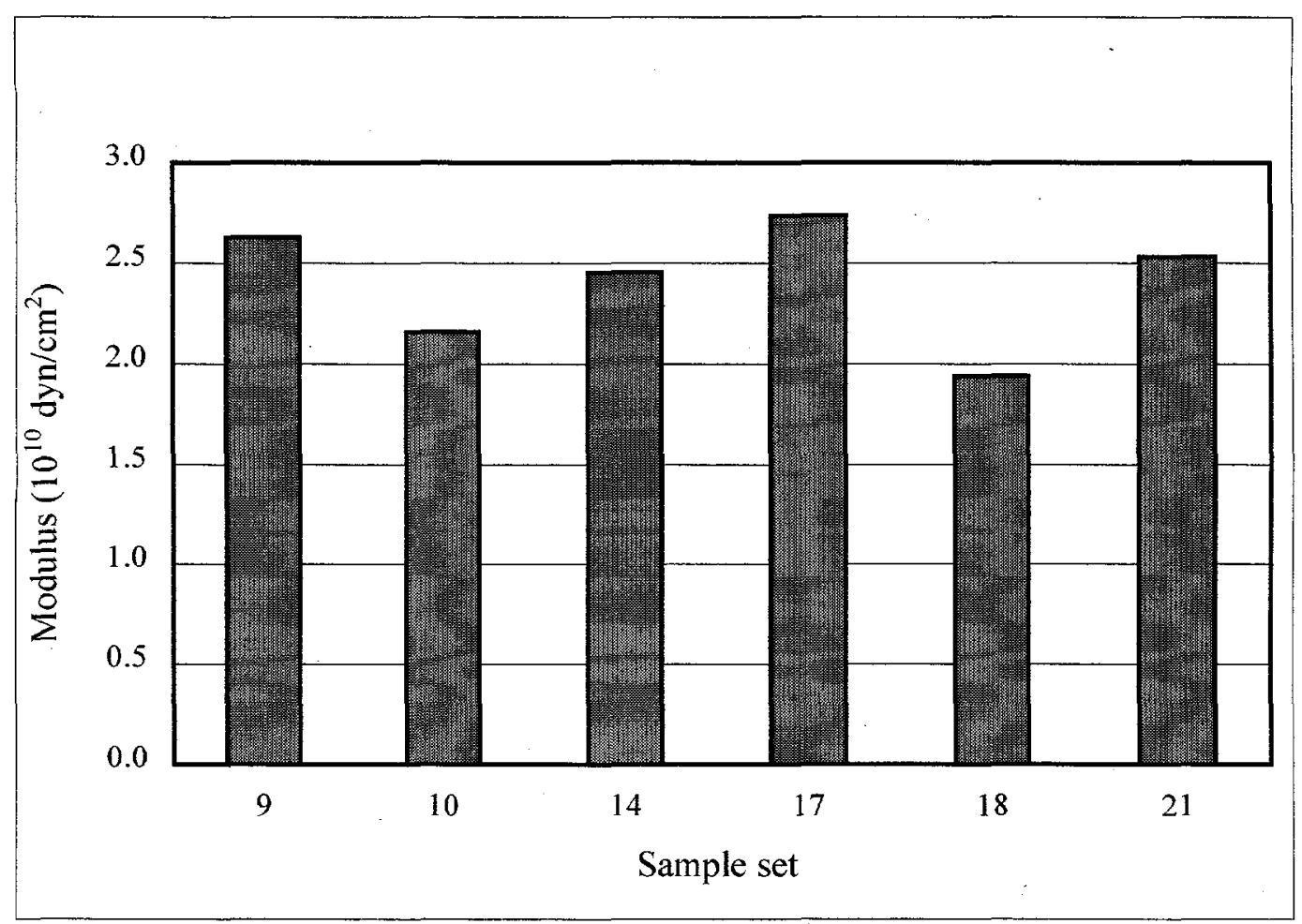

Figure 4. Flexural modulus (average values)

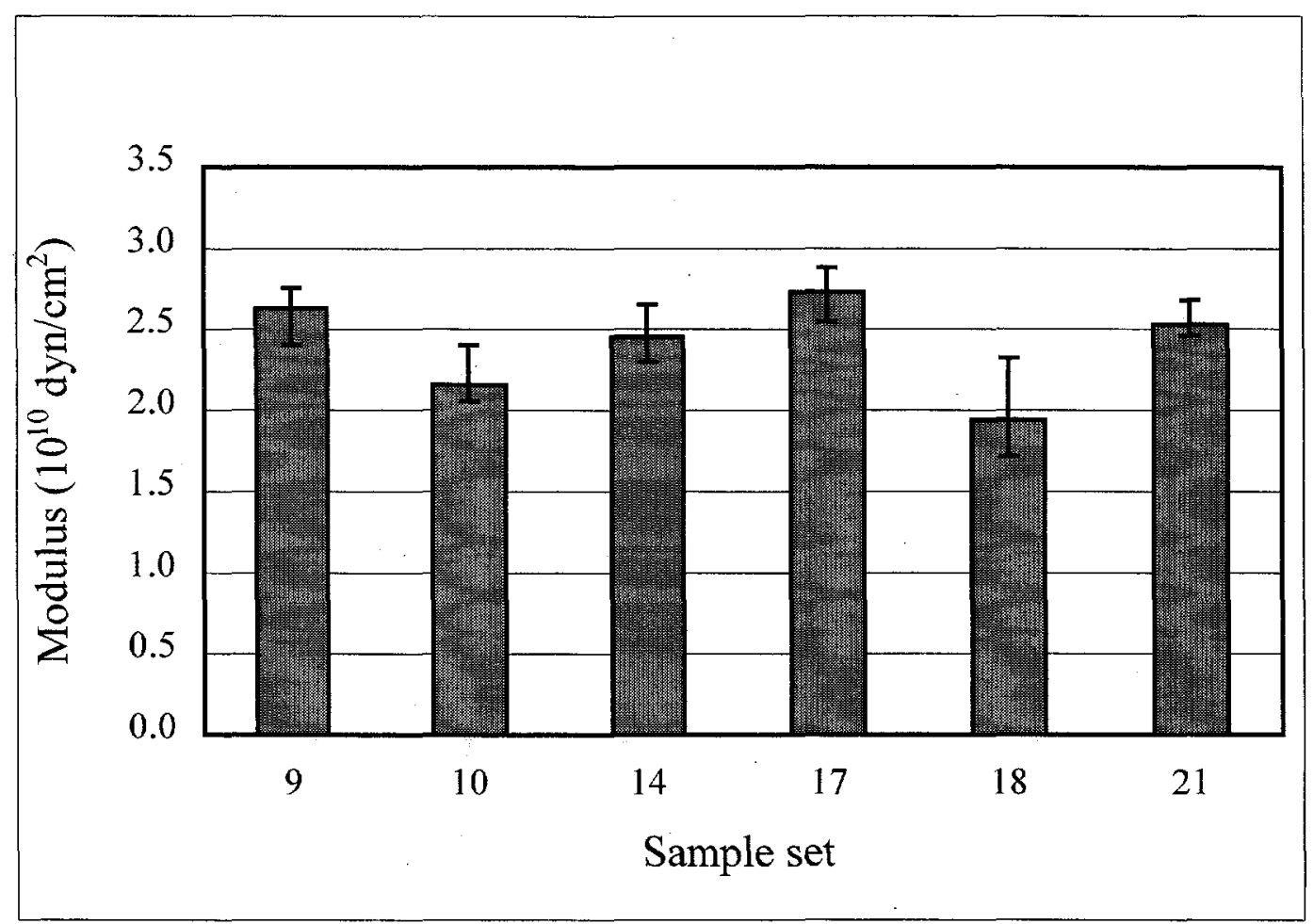

Figure 5. Flexural modulus (max and min bars) 


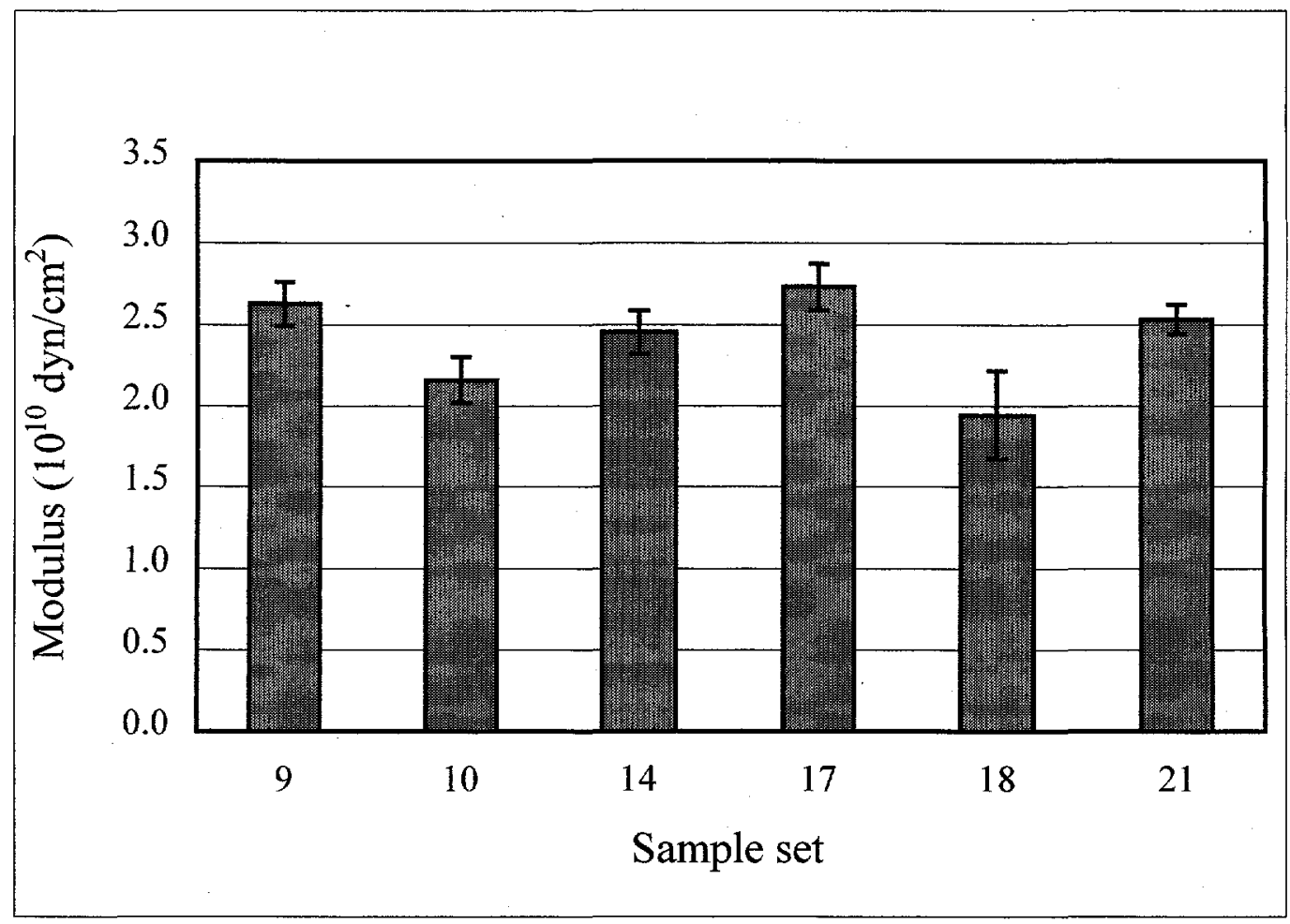

Figure 6. Flexural modulus (+/-st deviation error bars)

\section{Short Beam Shear Testing}

The apparent interlaminar shear strength was measured by the short beam method as per ASTM D2344. The samples were tested on an Instron 4505 with a crosshead speed of $1.3 \mathrm{~mm}$ per min. The maximum load was recorded and used to determine the shear strength of the materials, as shown in Table 2. The force versus displacement plots for the tests were similar, with a drastic drop in force after the initial break. The test was continued after the initial break, and the force again rose until a subsequent break ruined the integrity of the sample. Often, the initial break was accompanied by an audible crack. The average readings for each set are plotted in Figures 7 to 9 . 
Table 2. Short Beam Shear Data

Table 2: Short beam shear data

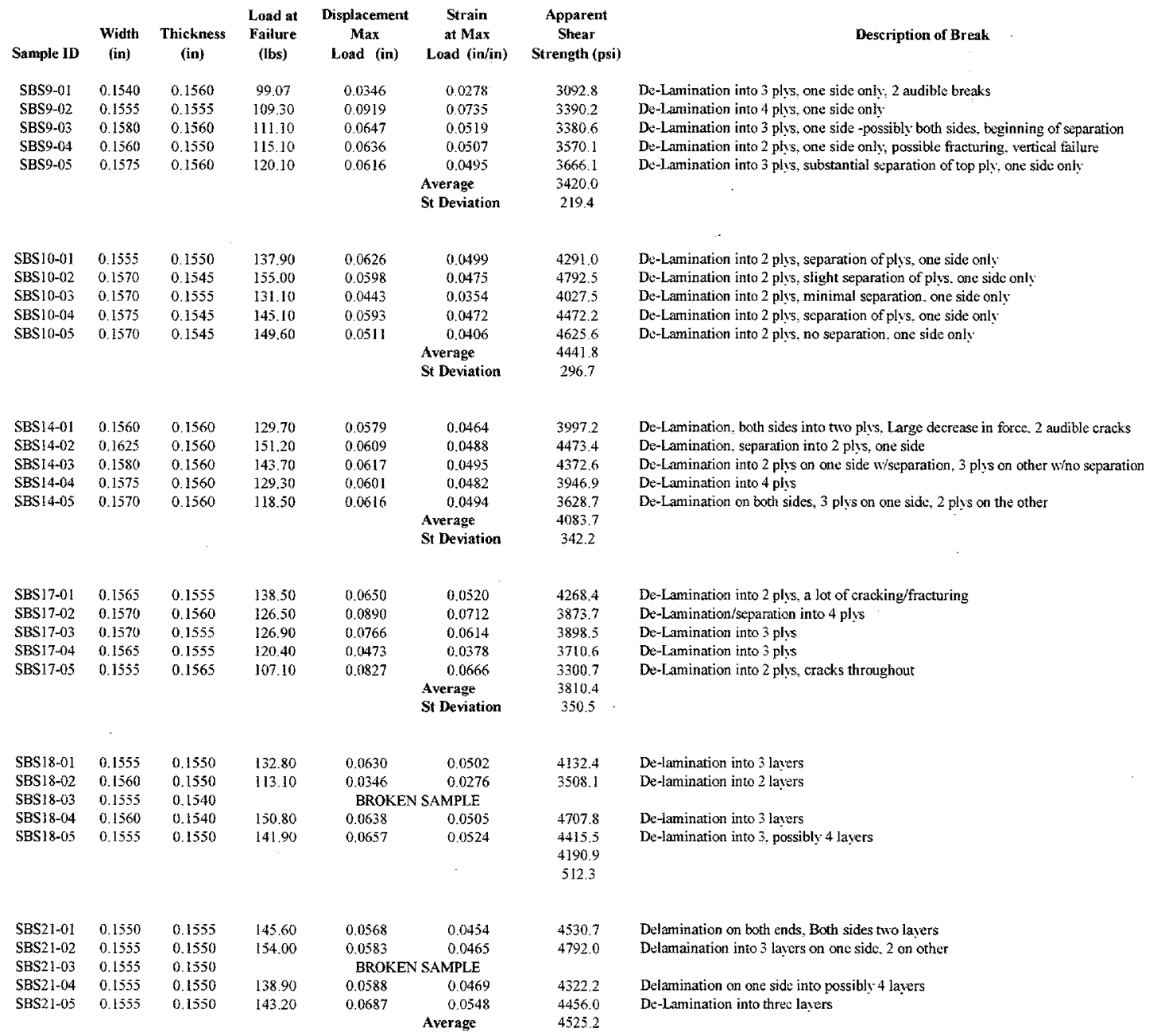



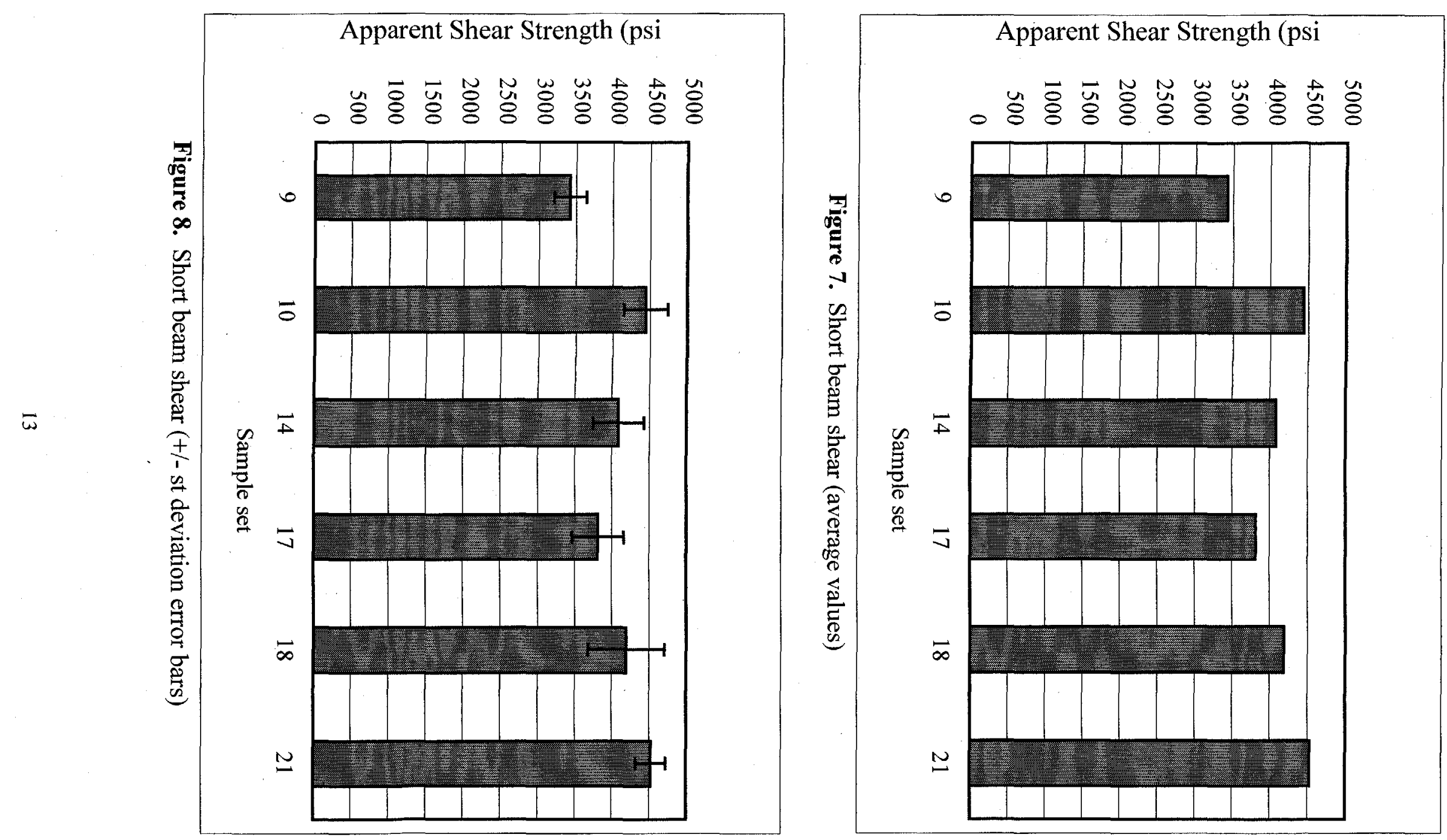


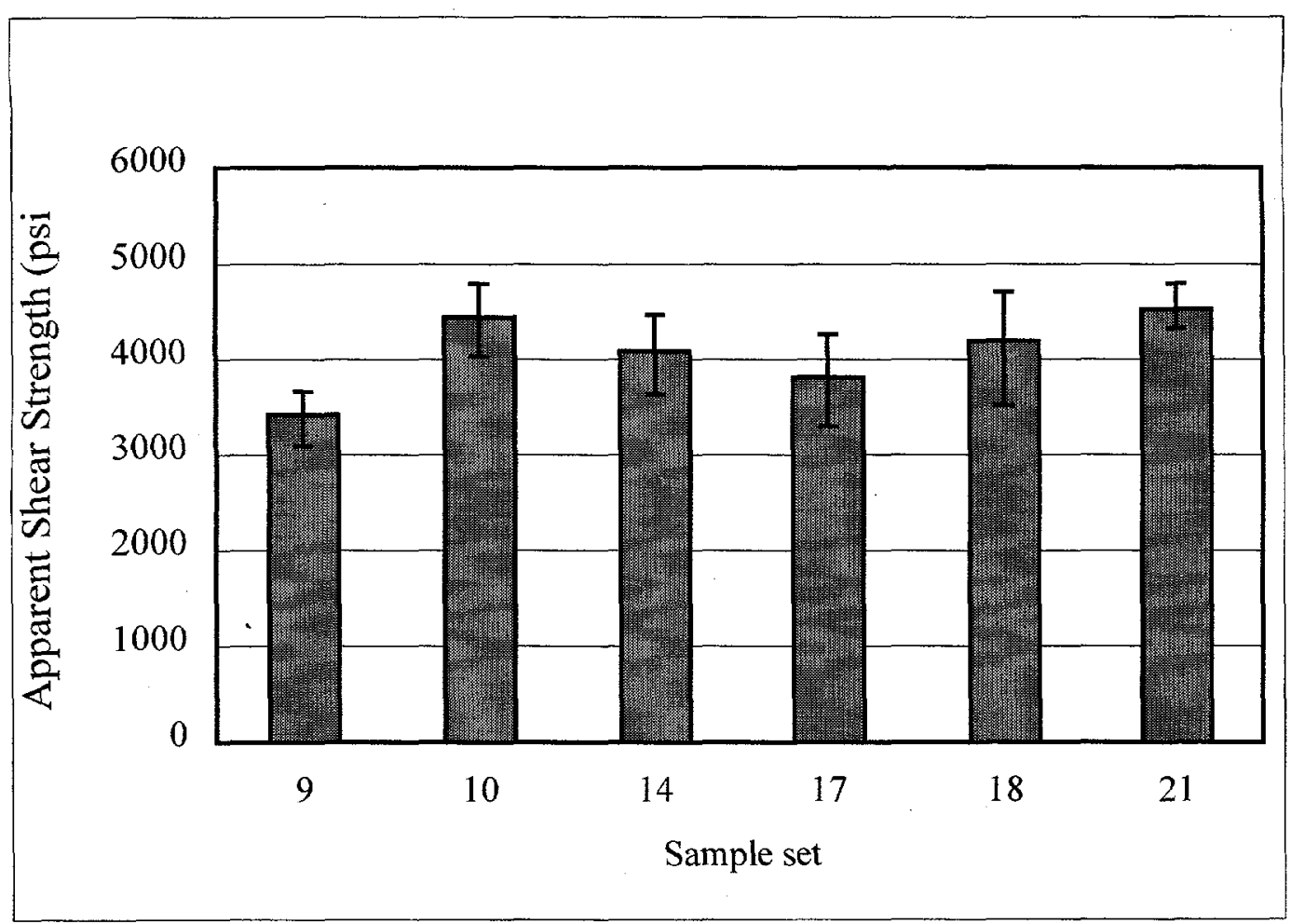

Figure 9. Short beam shear (max and min bars)

\section{Tensile Testing}

The tensile testing was based on guidance from ASTM D-3039 and the use of a 4505 Instron Universal Testing machine. The samples were prepared as outlined in the previous section and tested in tension at $1 \mathrm{~mm}$ per min. Table 3 shows the measured geometries and maximum loads at failure. A statistical analysis was performed on the data and Figures 10 and 11 show the mean tensile strength and modulus.

\begin{tabular}{|c|c|c|c|c|c|c|c|c|c|c|}
\hline \multirow{3}{*}{ Greige } & \multicolumn{10}{|c|}{ Table 3. Tensile Test Data (1/4" R Notched Specimens) } \\
\hline & $\underset{\text { ID }}{\text { SAMPLE }}$ & WIDTH & THICKNESS & AREA $\left(\mathrm{in}^{\wedge} 2\right)$ & $\operatorname{MAX}_{\text {LOAD }}$ & $\begin{array}{l}\text { MAX } \\
\text { STRESS }\end{array}$ & Modulus & Max Stress & & Modulus \\
\hline & $77-01$ & 0.2510 & 0.0605 & 0.01519 & 720.1 & 47420 & 14517 & Mean & 47234 & 12579 \\
\hline & T7-02 & 0.2550 & 0.0605 & 0.01543 & 732.7 & 47493 & 10288 & Standard Error & 509 & 497 \\
\hline & $77-03$ & 0.2545 & 0.0605 & 0.01540 & 753.4 & 48931 & 12292 & Median & 47493 & 12562 \\
\hline & T7-04 & 0.2530 & 0.0615 & 0.01556 & 693.0 & 44539 & 12562 & Standard Deviation & 1346 & 1316 \\
\hline & $T 7-05$ & 0.2540 & 0.0615 & 0.01562 & 731.5 & 46828 & 13499 & Sampie Variance & $\begin{array}{c}18121 \\
59\end{array}$ & 1731741 \\
\hline & T8-01 & 0.2620 & 0.0610 & 0.01598 & 762.8 & 47729 & 11988 & Range & 4392 & 4229 \\
\hline & T8-02 & 0.2590 & 0.0615 & 0.01593 & 759.8 & 47701 & 12907 & Minimum & 44539 & 10288 \\
\hline & & & & & & & & Maximum & 48931 & 14517 \\
\hline & & & & & & & & Sum & $\begin{array}{c}33064 \\
0\end{array}$ & 88053 \\
\hline & & & & & & & & Count & 7 & 7 \\
\hline \multicolumn{11}{|l|}{$\operatorname{cs} 724$} \\
\hline & T11-05 & 0.2500 & 0.0610 & 0.01525 & 671.1 & 44007 & 17260 & Mean & 42351 & 14161 \\
\hline & $T 11-06$ & 0.2520 & 0.0610 & 0.01537 & 665.6 & 43300 & 14085 & Standard Error & 698 & 995 \\
\hline
\end{tabular}




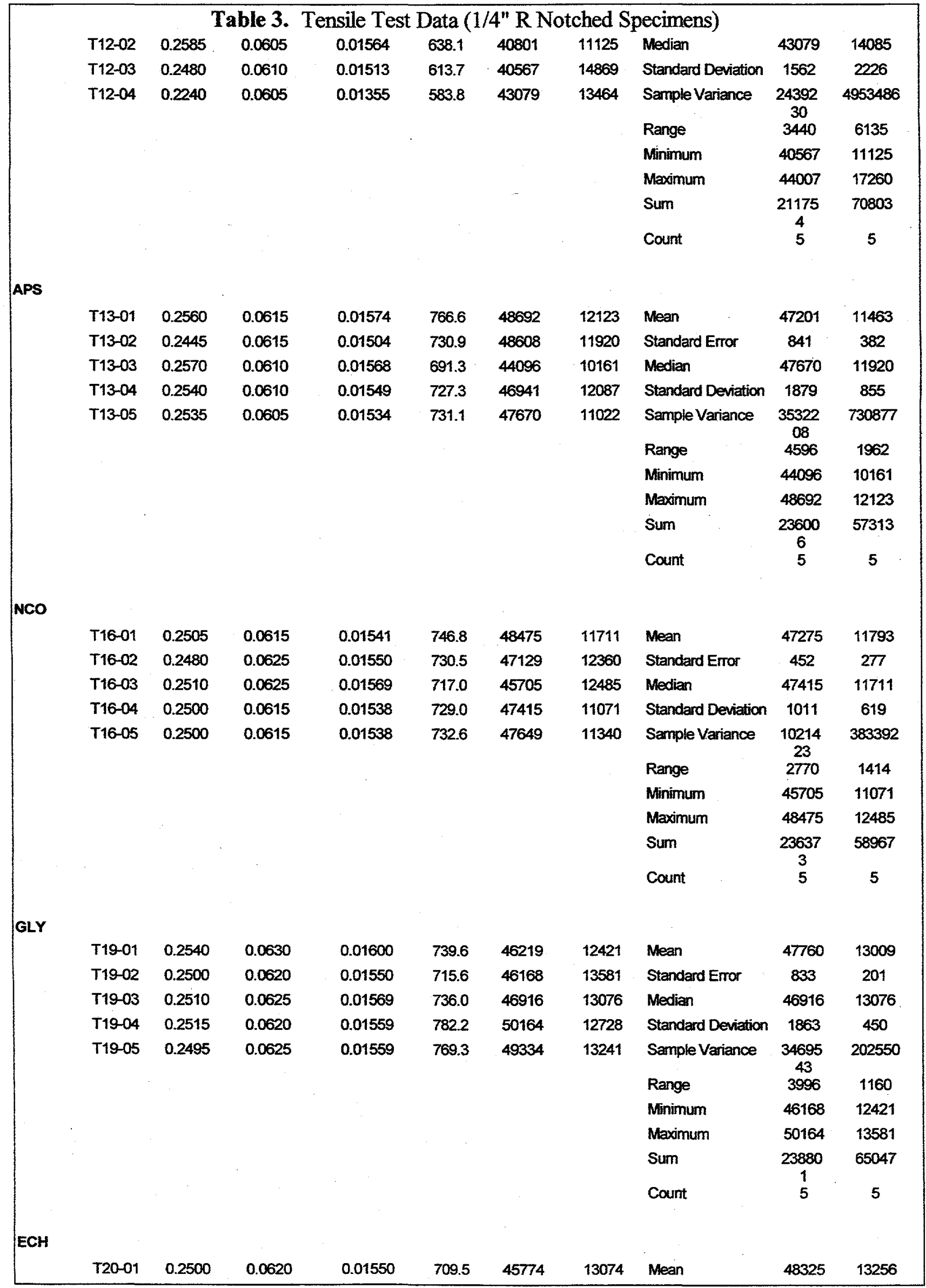




\begin{tabular}{|c|c|c|c|c|c|c|c|c|c|}
\hline \multicolumn{10}{|c|}{ Table 3. Tensile Test Data (1/4" R Notched Specimens) } \\
\hline $\mathrm{T} 20-02$ & 0.2495 & 0.0620 & 0.01547 & 748.8 & 48406 & 13600 & Standard Error & 724 & 322 \\
\hline$T 20-03$ & 0.2500 & 0.0625 & 0.01563 & 757.2 & 48461 & 12265 & Median & 48461 & 13129 \\
\hline$T 20-04$ & 0.2485 & 0.0615 & 0.01528 & 768.4 & 50279 & 13129 & Standard Deviation & 1620 & 719 \\
\hline $\mathrm{T} 20-05$ & 0.2505 & 0.0625 & 0.01566 & 762.5 & 48703 & 14214 & Sample Variance & $\begin{array}{c}26234 \\
14\end{array}$ & 516858 \\
\hline & & & & & & & Range & 4505 & 1949 \\
\hline & & & & & & & Minimum & 45774 & 12265 \\
\hline & & & & & & & Maximum & 50279 & 14214 \\
\hline & & & & & & & Sum & $\begin{array}{c}24162 \\
3\end{array}$ & 66282 \\
\hline & & & & & & & Count & 5 & 5 \\
\hline
\end{tabular}

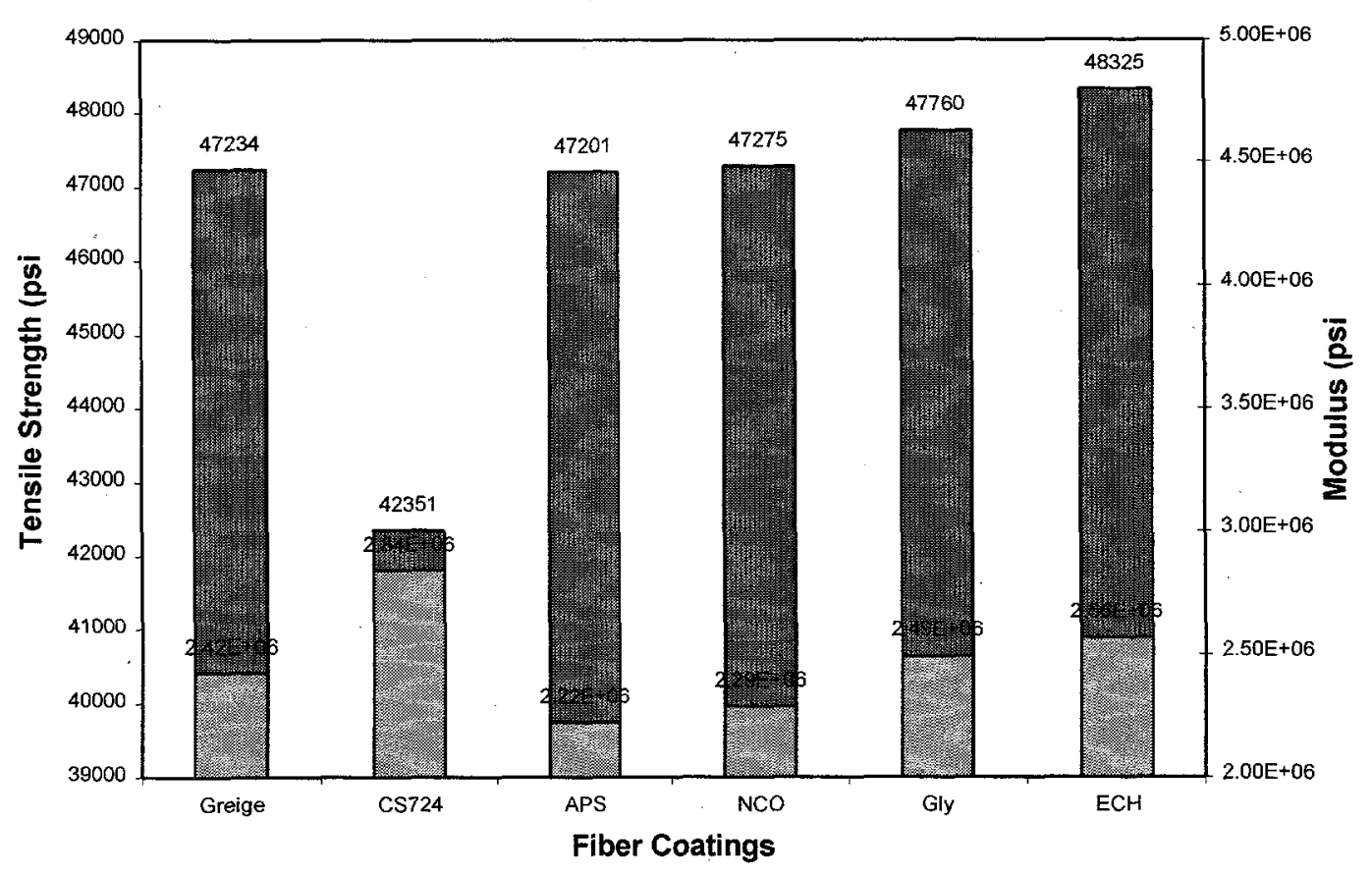

Figure 10. Comparison of Modulus and Strength 


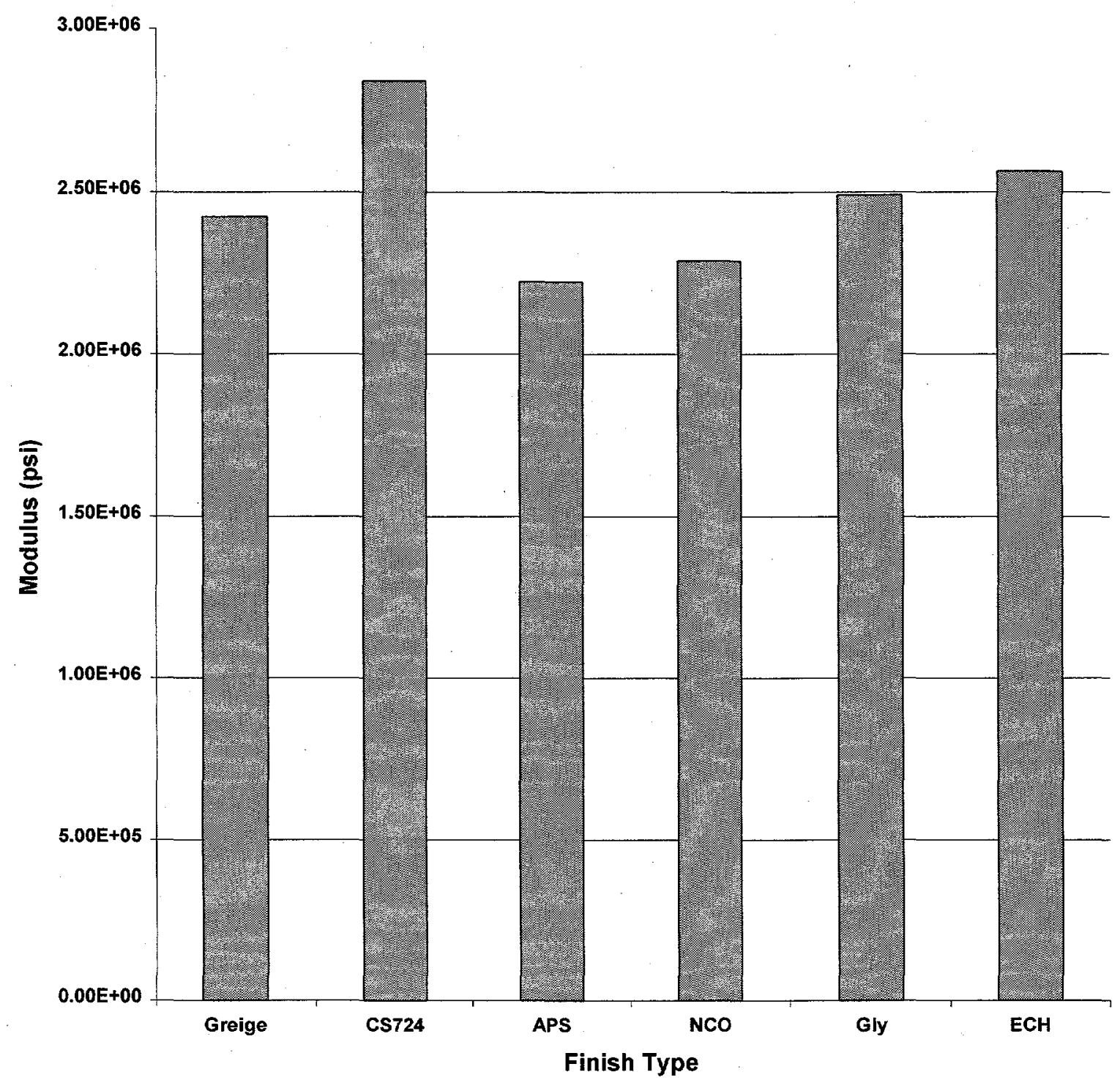

Figure 11. Tensile Modulus 


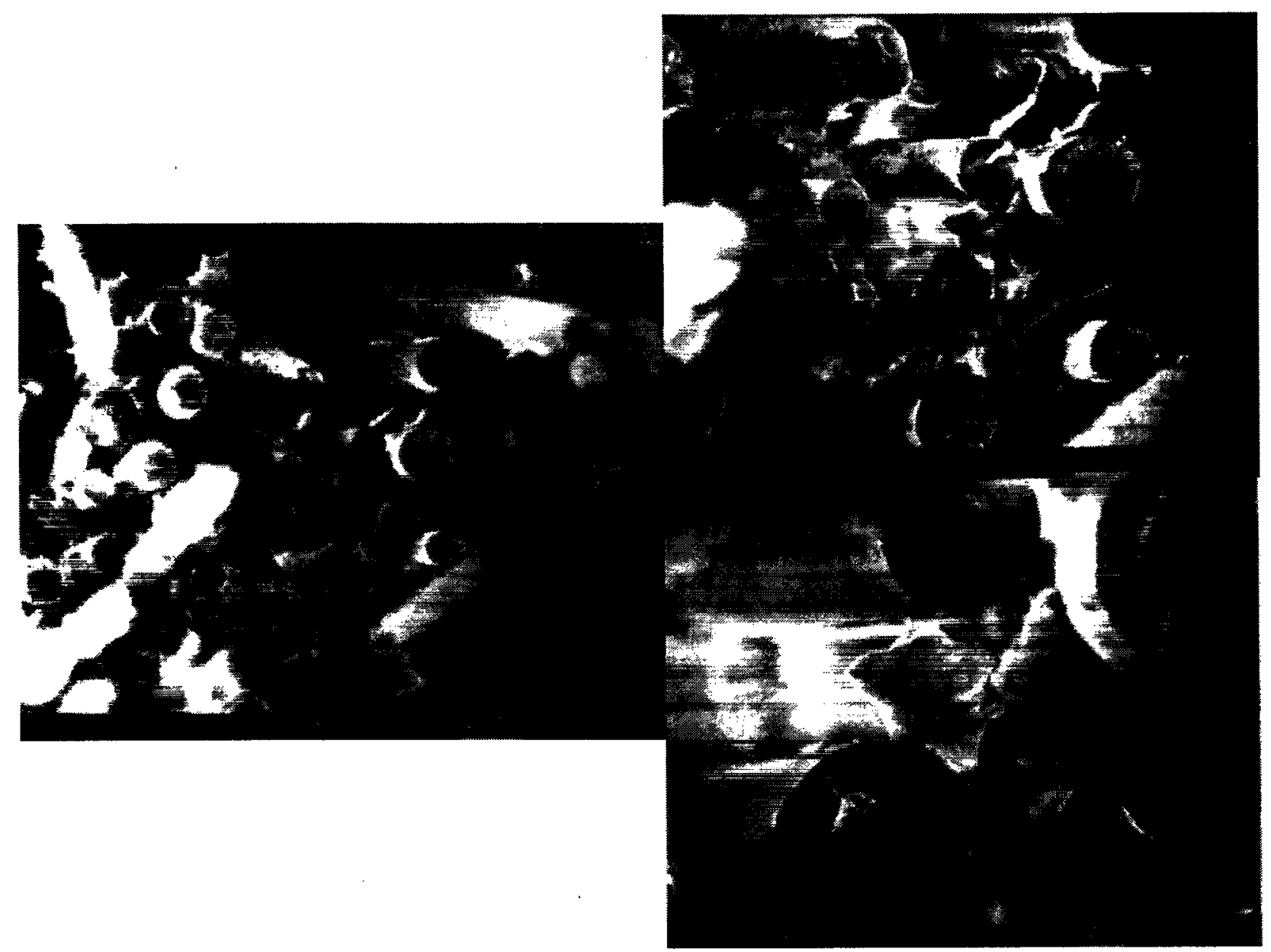

Figure 12. Scanning electron microscopy (SEM) of ECH SAM tensile fracture (see Appendix B for more SEMs)

\section{Thermoplastic Phase}

\section{Task 1: Research}

\section{Research for Optimum SAMs for AS-4 Fibers and PEI}

A search for optimizing available oxygen containing molecules for attaching SAMs to the surface of the carbon fibers. Alternative mild oxidation techniques were looked at and tested on carbon fibers for examining fiber damage vs. increase oxygen content on the surface.

The SAM molecules that will be attempted on carbon fiber appear to be the molecules that were done on the glass fiber studies and some others will be attempted. This effort will be looked at in FY99 research efforts. 


\section{Research on Coating Fibers with PEI}

A search was completed for different techniques of coating carbon fiber bundles for testing the materials as the are treated. The Army fibers are hot melt polyetherimide coated fibers and different techniques are used for coating them. One method is an extrusion die with a slit for fiber bundles to be pulled through the high-pressure die while impregnating the fibers. Other companies' solvents impregnate and then go through multiple steps for removing the solvent. Solvent impregnation is not an option for the Army.

\section{Task 2: SAMS}

SAM coatings on carbon fibers have been examined and determined, based on task 1 research, that it is feasible to apply these types of coatings and potentially see improvements in properties.

\section{Task 3: Fabrication}

Fabrication method for the AS-4/PEI Panels for Test Specimens has been developed for use in the FY99. Unidirectional plates will be fabricated and test specimens of flexural, short-beam shear and tensile will be cut from the fabricated plates.

\section{Task 4: Testing}

No testing was performed during FY98 on thermoplastic carbon fibers, but specimen sizes and parameters were developed for future FY99 testing. 



\section{Results and Conclusions}

The first phase in FY97 demonstrated that it is possible to increase the adhesive strength, as well as increase the heat deflection temperature through the use of SAMs. Work in FY98 focused on glass fiber composites and their bulk properties. The bulk properties testing of composite laminates were made from different glass fiber surface treatments that were done on tensile, flexural, and short-beam shear specimens.

Figure 13(a) shows the load transfer mechanism for a single glass fiber embedded in a matrix material that is subjected to axial loading. The matrix material that is typically between the single fibers transfers the subjected load to the fibers. Upon the load transfer from the matrix to the glass fiber, shear stresses build at the fiber/matrix interface. The interface is the key to developing a strong composite material. The shear stresses have high values near the ends of fibers, such as a fiber break, and decrease as function of distance from the fiber end. The tensile stress in the glass fiber does just the opposite. The tensile stress increases as a function of distance from the glass fiber end and if the tensile strength of the fiber is exceeded, the fiber fails and delamination from shear stress begins, as shown in Figure 13(c).

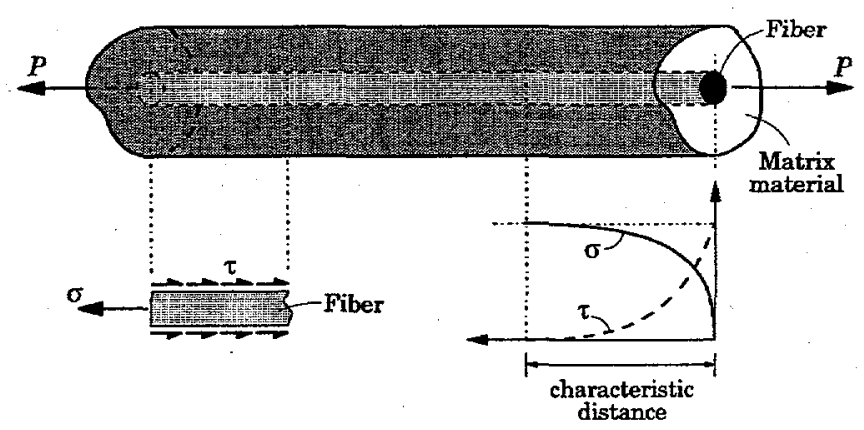

(a)

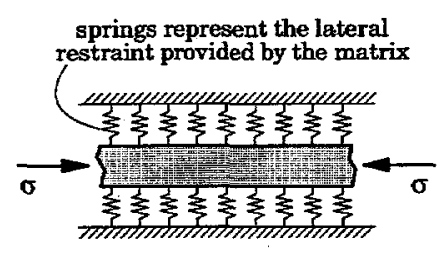

(b)

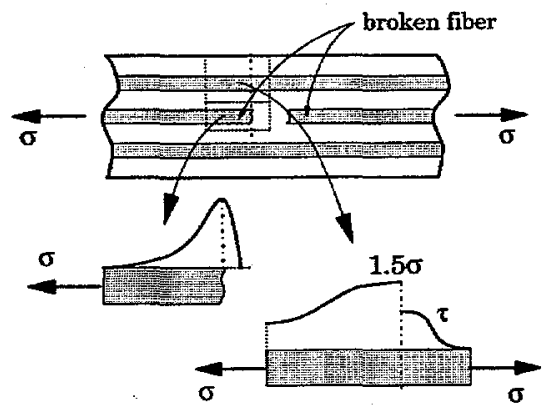

(c)

Figure 13. Load transfer stress distributions in a single fiber embedded in a matrix material and subjected to an axial load. (Reference: Mechanics of Laminated Composite Plates: Theory and Analysis, J.N. Reddy, CRC Press, New York, 1997) 
The SAM treatments on glass fibers have demonstrated an improved affect in the overall composite bulk properties. The improvements can be explained by Figures 3 and 13(b) in how it works and why. Figure 3 shows how the matrix material for a thermoset system can be chemically bonded to the glass fiber surface. The chemical bonding takes place through the curing mechanism called crosslinking. The epoxy resin can be crosslinked to the surface of the chemically prepared surface or epoxide groups on the glass fiber surfaces can be cross-linked with the curing agent that has been mixed in with the epoxy resin. The research applied various SAM treatments to the glass fiber mats and compared them to a non-surface treated glass fiber system and a commercially available glass fiber. Once the resin system is crosslinked and cured, the SAM affects the adhesion to the surface of the glass fiber and as well as the modulus in the interphase region. Figure 13(b) demonstrates how the interphase works as springs. The different types of SAMs can control the spring constants or modulus of the material. The tensile test shows the effect that the SAMs have on the strength of the material. The ECH SAM showed the highest tensile strength as well as the highest short-beam shear. The other SAMs show some improvements but the properties were anticipated to be different. The other SAMs testing data demonstrates that by controlling the chemical interface with the SAM system, the properties can be tailored to what is desired. For instance, if a toughened system is desired, a lower modulus interface can be applied.

Using the proof-of-principle that SAMs can improve the properties of polymeric glass fiber composites, the use of SAMs on polymeric thermoplastics on carbon fiber was investigated. The initial work examined what was available to attach to on the surface of the carbon fiber and if additional oxidation treatments were going to be needed. Some gentle oxidation treatments were done and SEMs were completed. 
Appendix A

Raw Data of Tensile Testing 


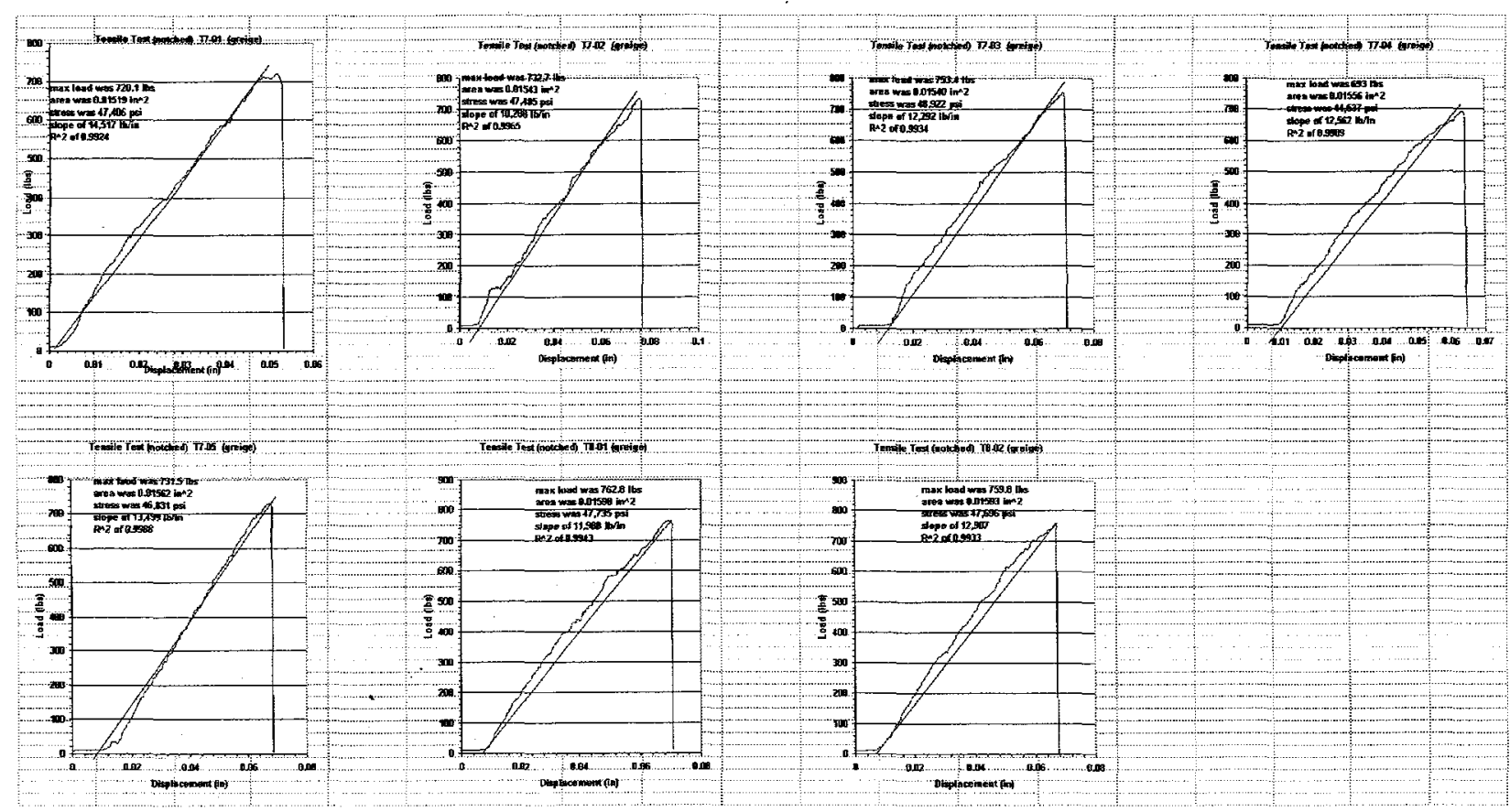

Figure A-1. Griege Raw Data

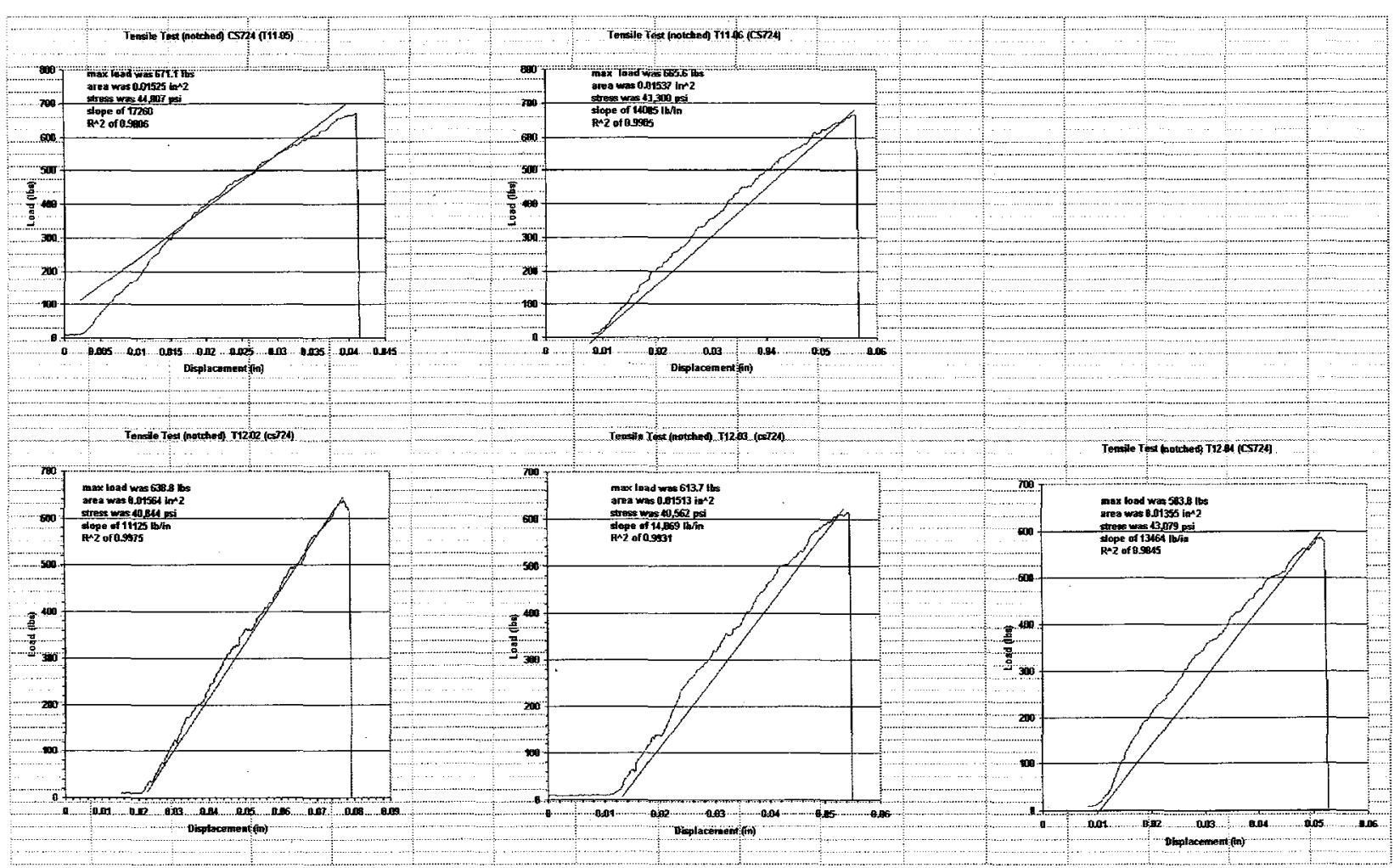

Figure A-2. CS 724 Commercial Material Raw Data 


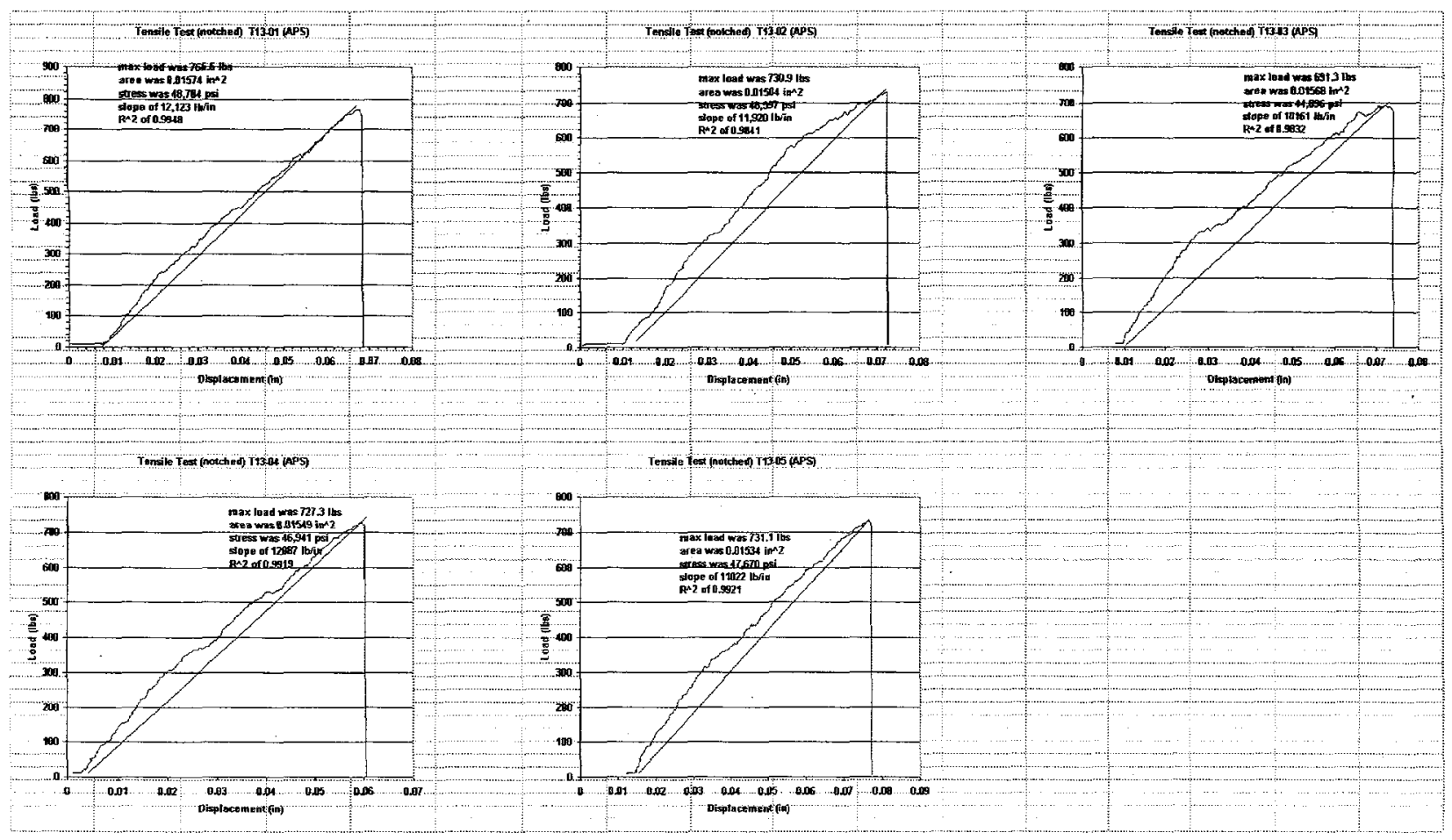

Figure A-3. APS SAM Treatment Raw Data

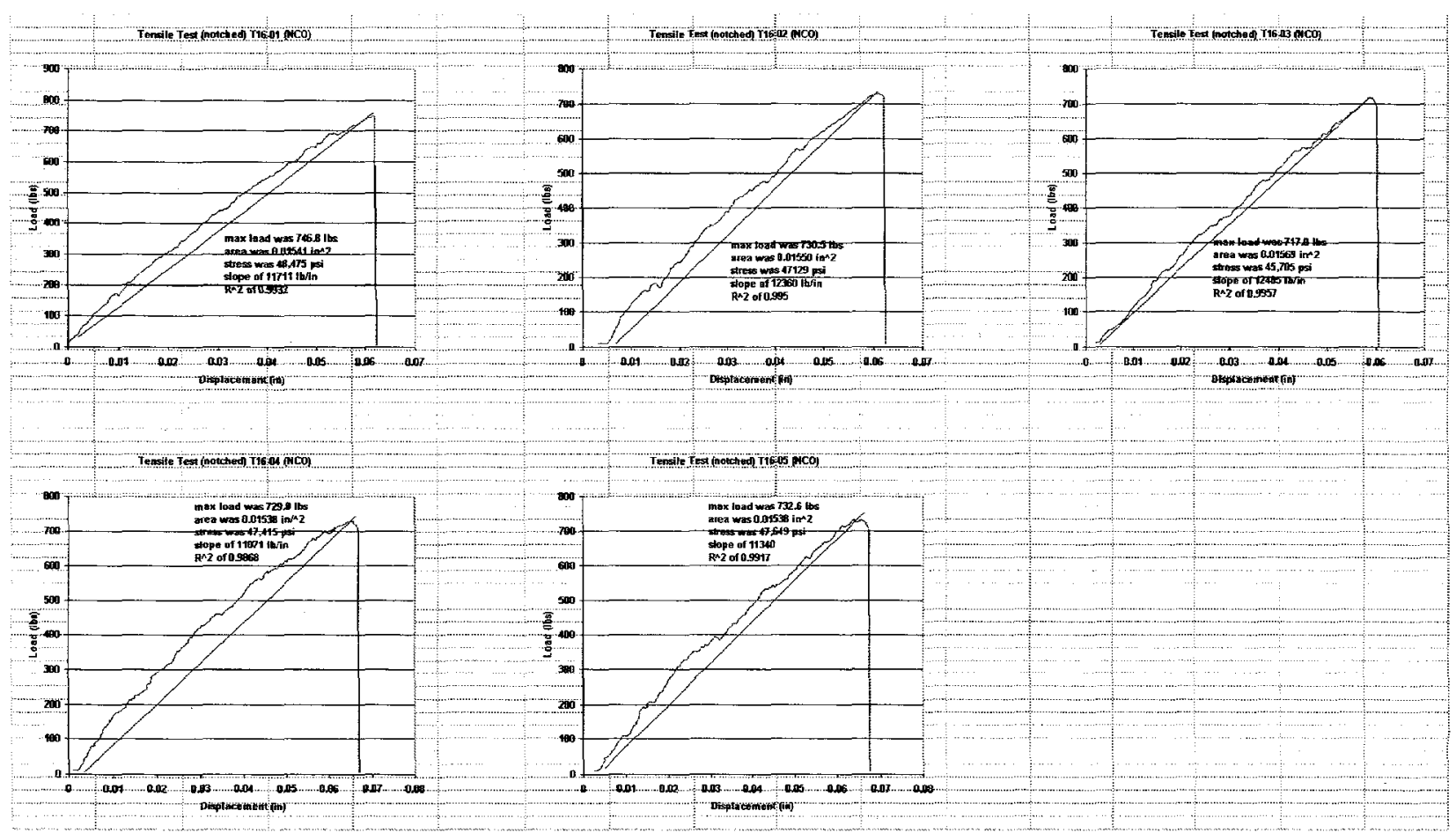

Figure A-4. NCO SAM Raw Data 


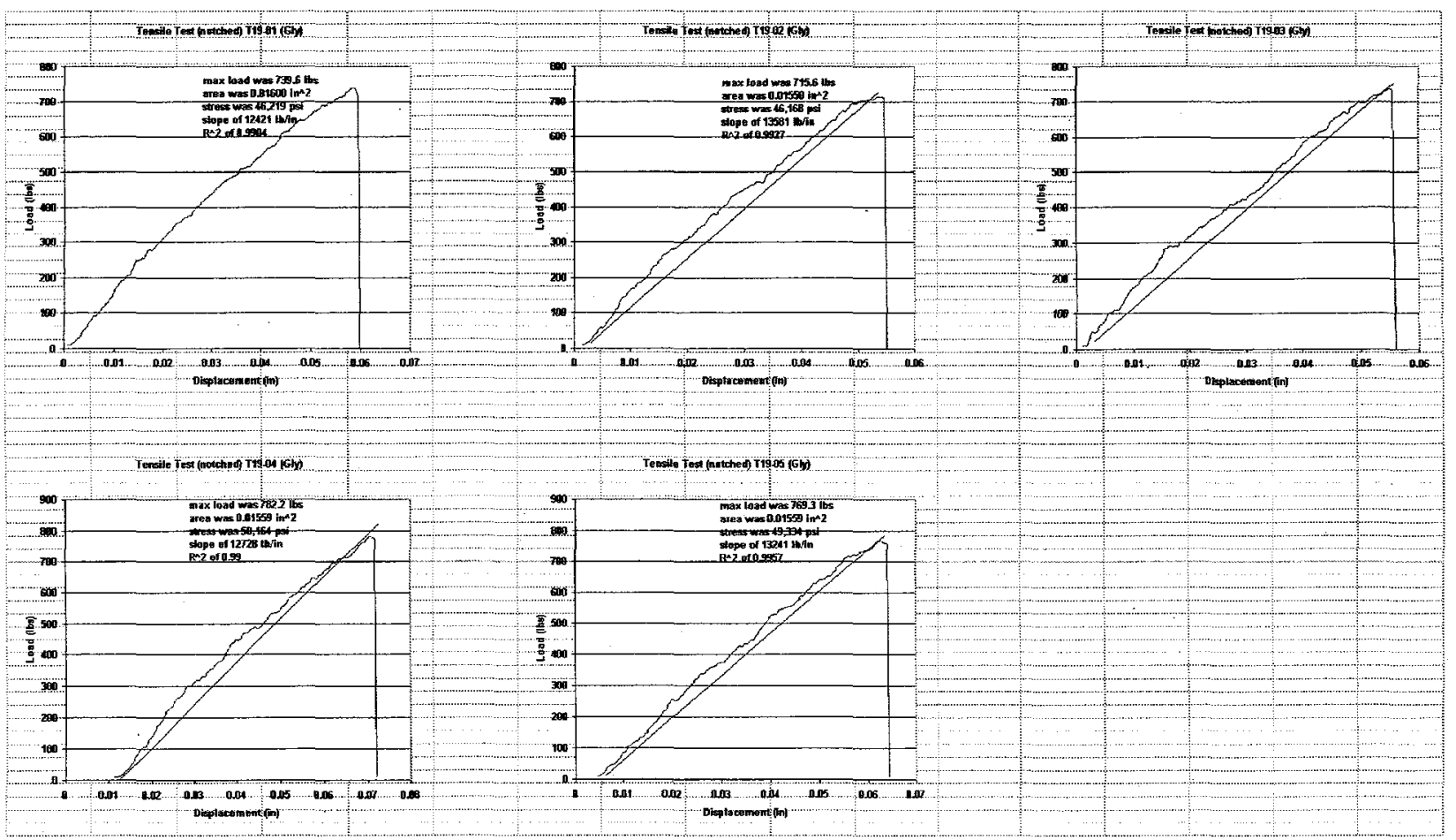

Figure A-5. GLY SAM Raw Data

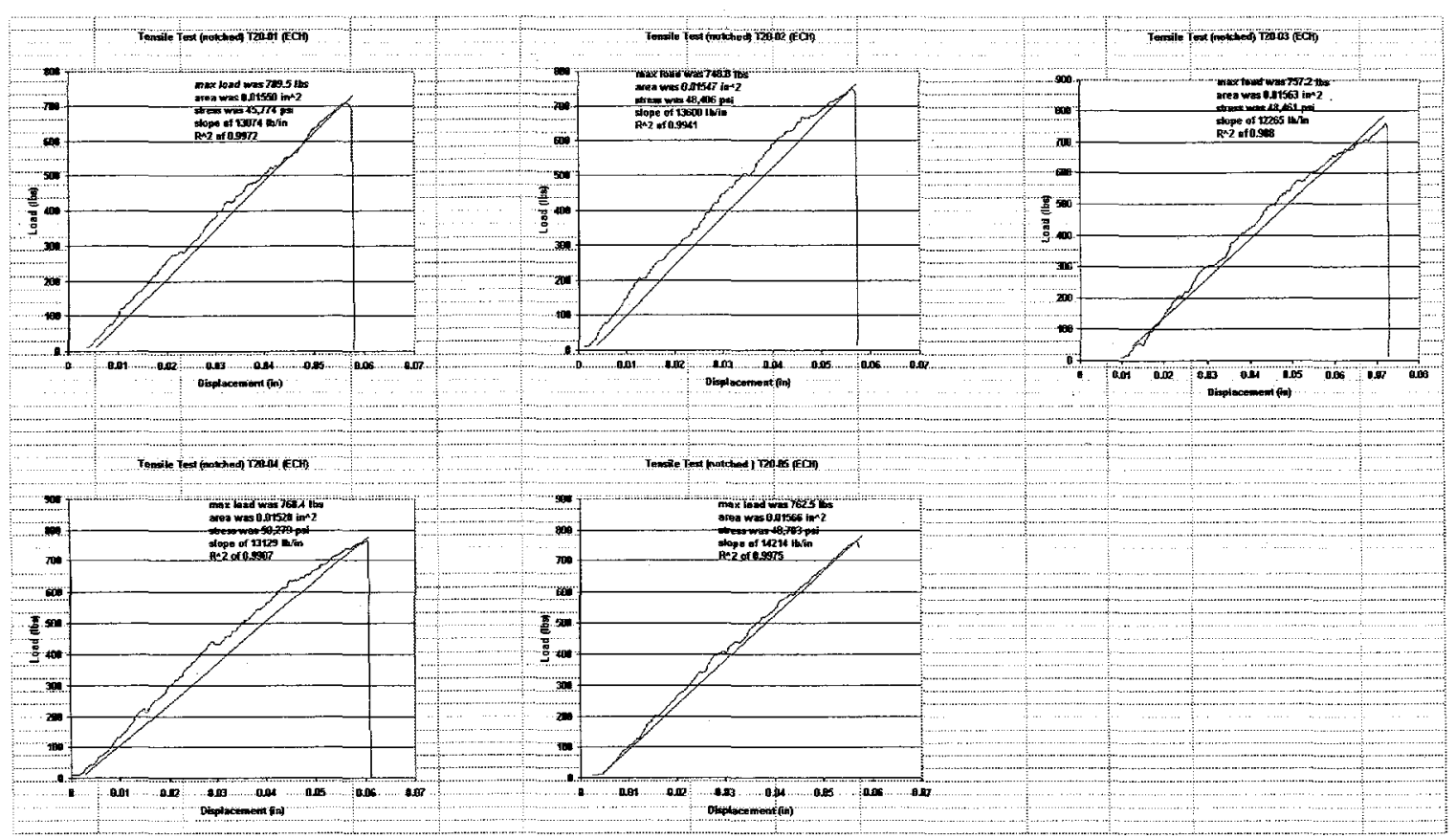

Figure A-6. ECH SAM Raw Data 
Appendix B

Scanning Electron Microscopy:

Tensile Test Specimen Fracture Areas 


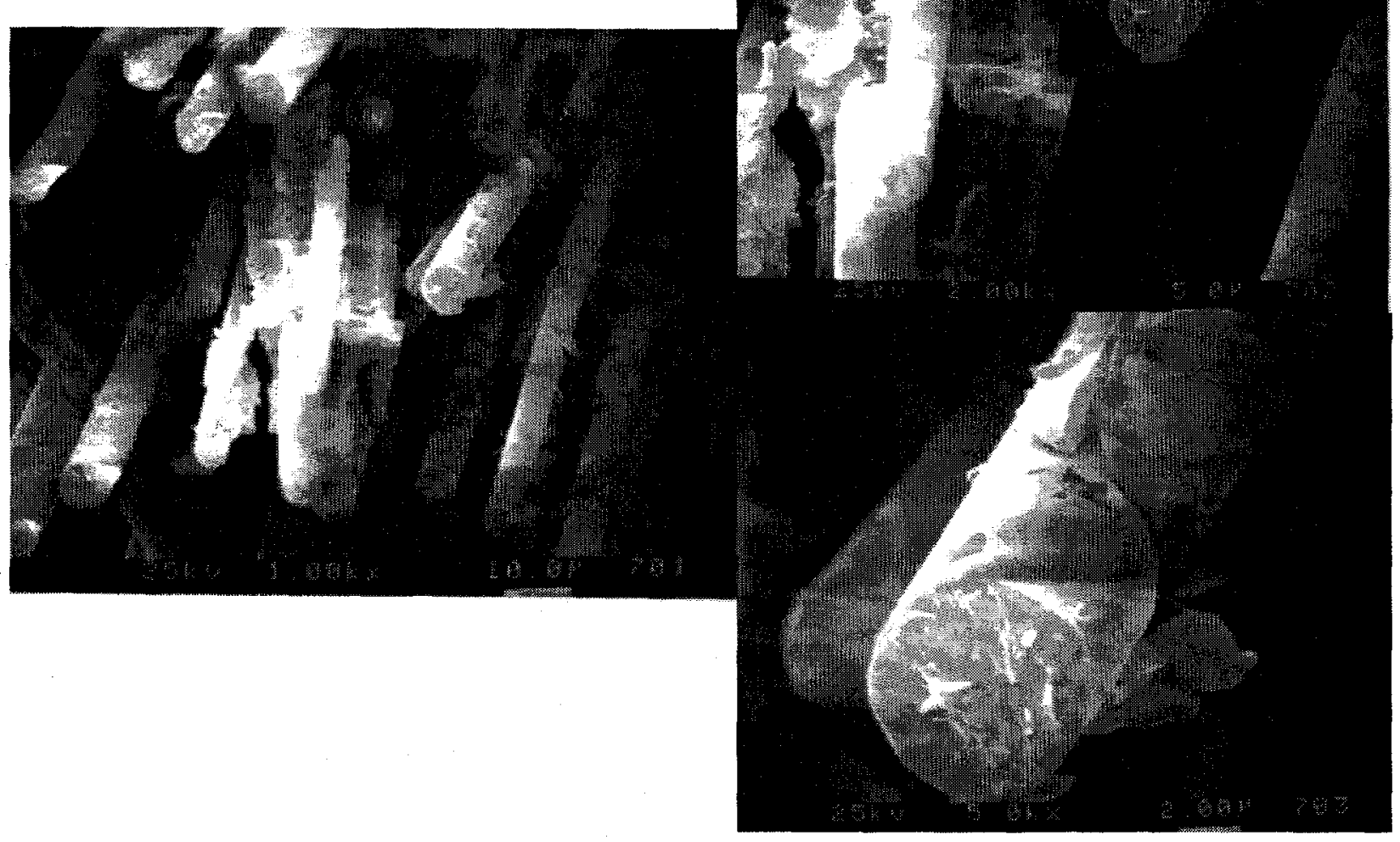

Figure B-1. Greige fiber tensile failure SEM
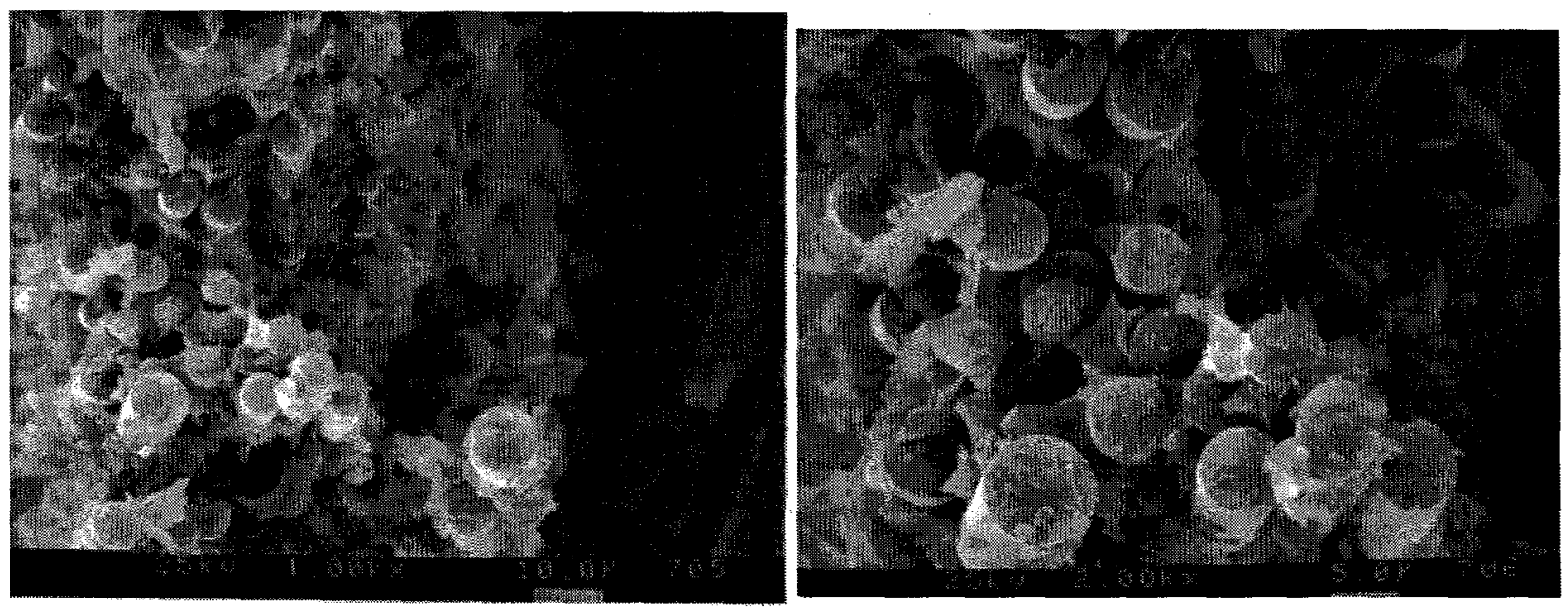

Figure B-2. SEM of tensile failure area from a CS 724 commercial surface treatment of glass fibers 


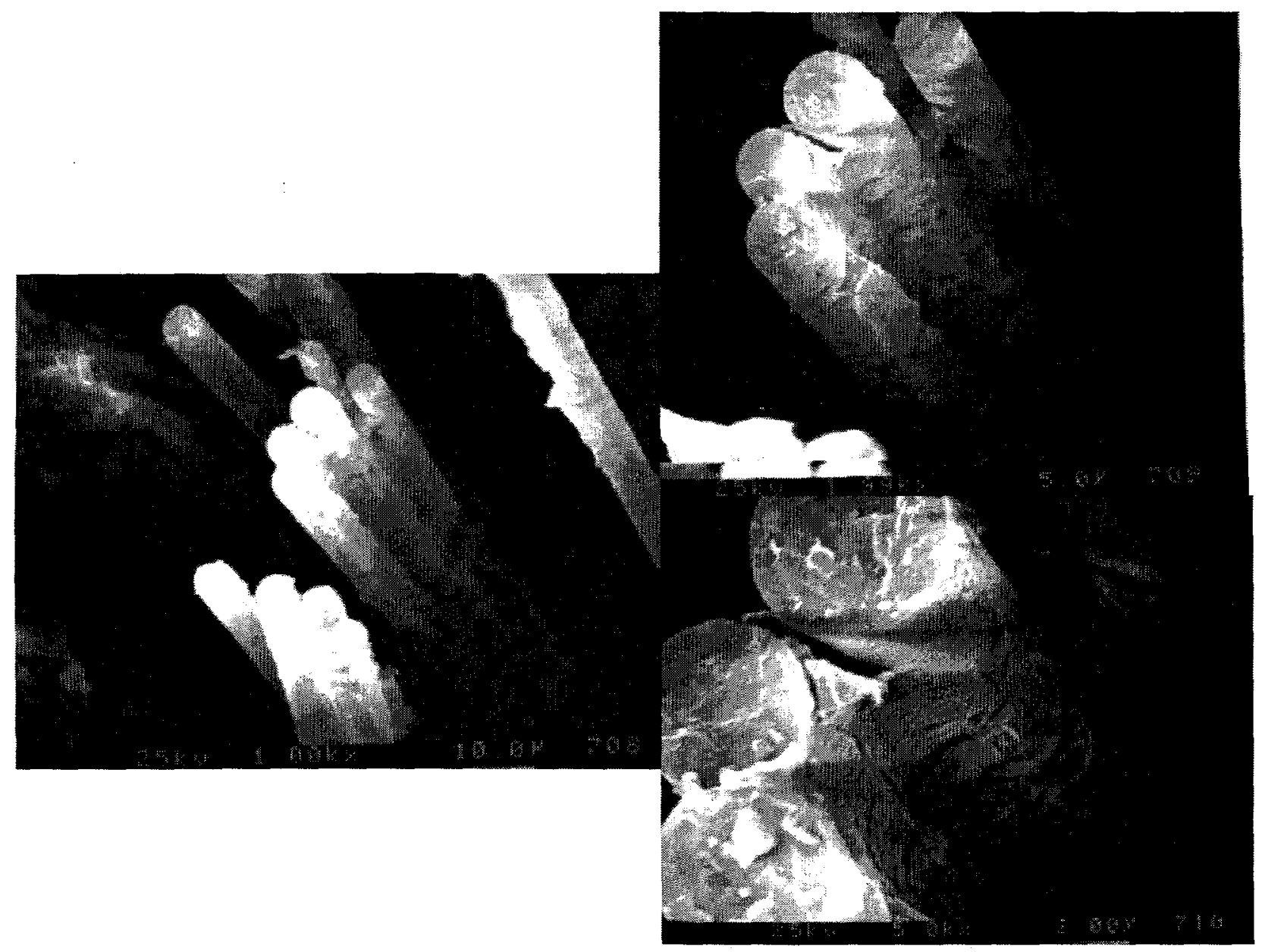

Figure B-3. SEM of tensile failure of an APS SAM-coated glass fibers 


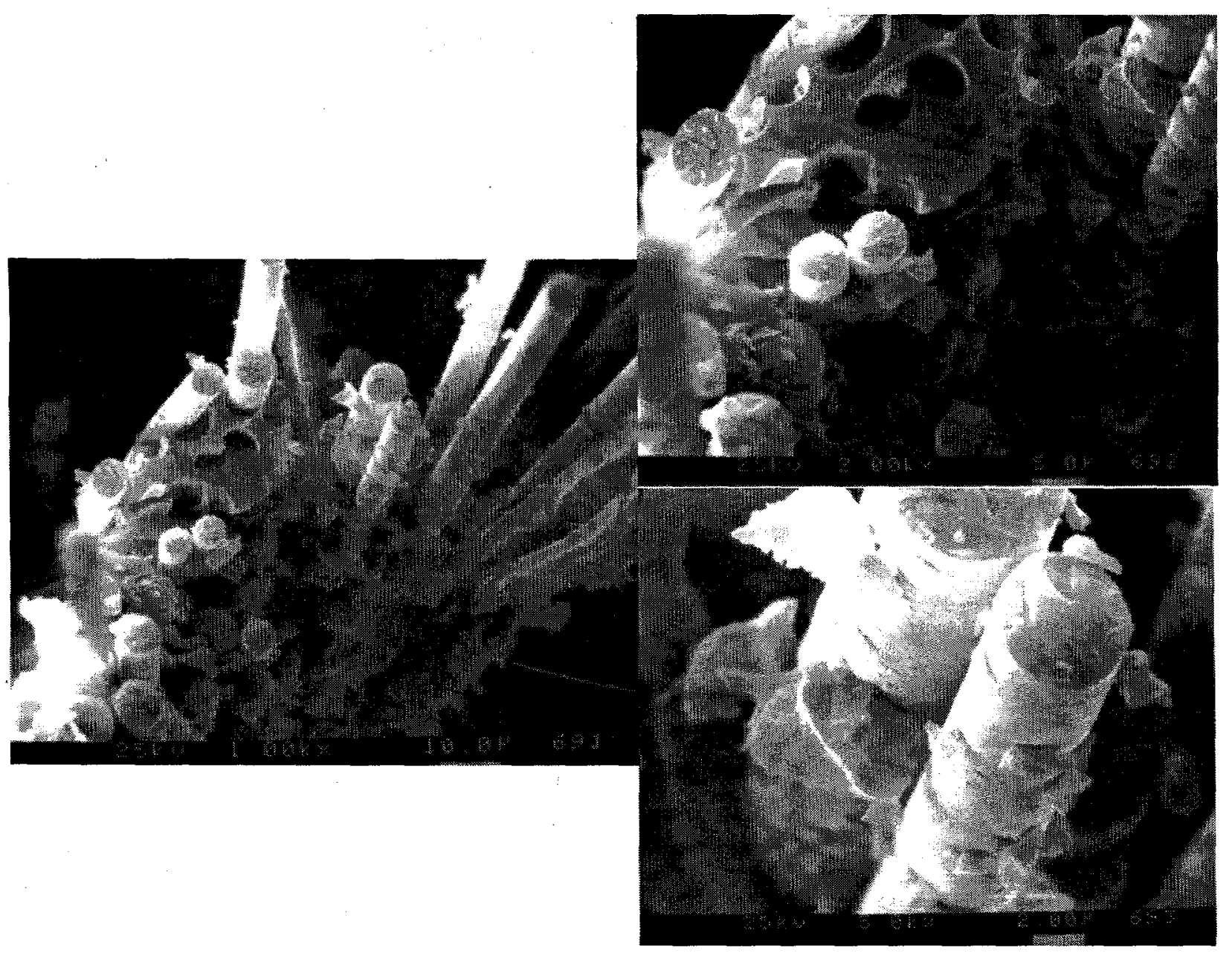

Figure B-4. SEM of tensile failure in NCO SAM-treated glass fibers 

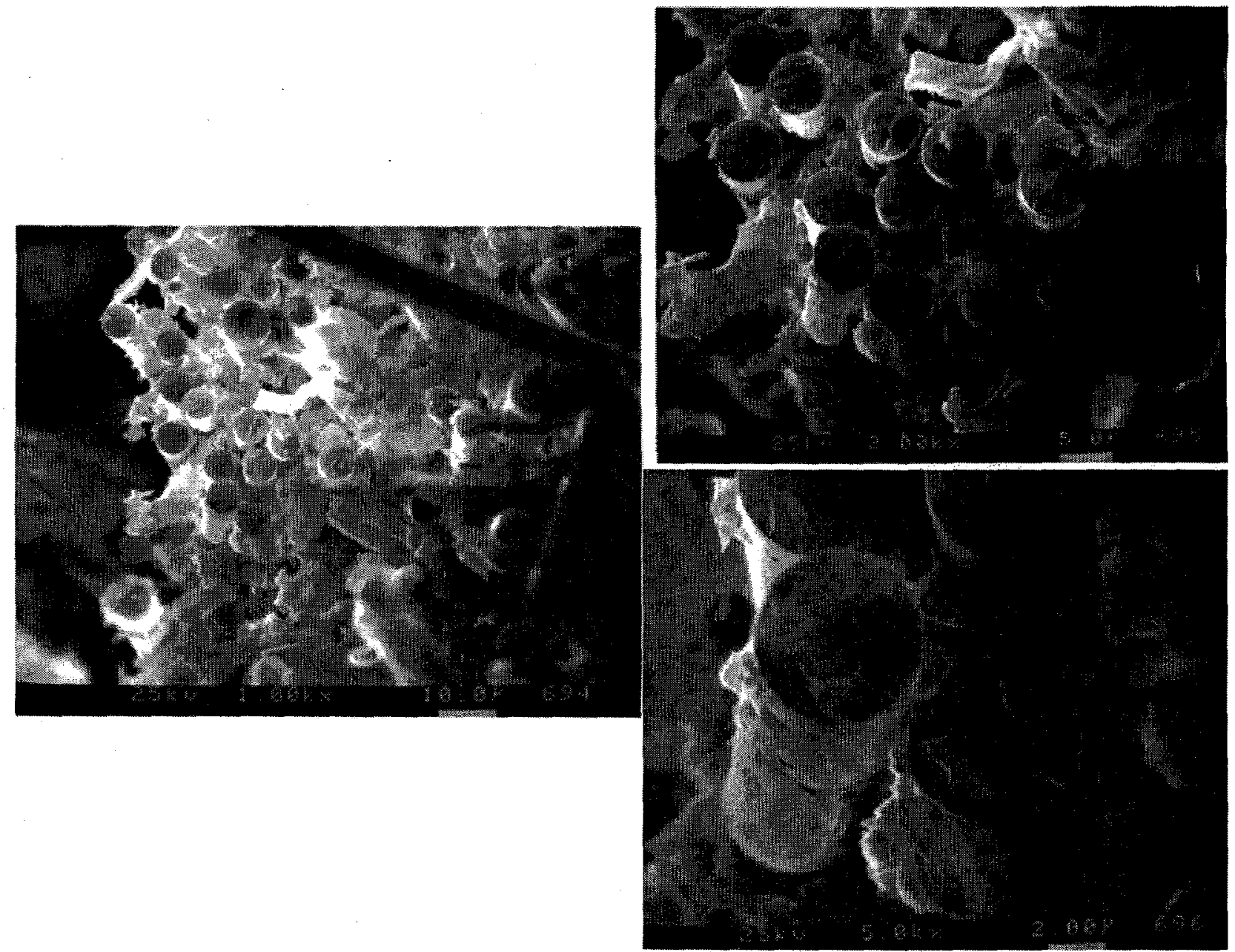

Figure B-5. SEM of tensile failure in GLY SAM-coated glass fibers 


\section{Distribution}

No. of Copies

Offsite

Commander (12)

Armament Research, Development and Engineering Center

U.S. Army Tank-Automotive and

Armaments Command

Picatinny Arsenal, NJ 07806-5000

ATTN:

AMSTA-AR-WE, J. Lannon

T. McWilliams

AMSTA-AR-WEA, C. Anderson, Jr.

J. Brescia

F. McLaughlin

T. Woo

AMSTA-AR-WES, C. Osiecki
A. Gonsiska
F. Del Carmen
G. Karshina
D. Fair
B. Perlmutter

Defense Technical Information Center (DTIC)

8725 John J. Kingman Road, Ste 0944

Fort Belvoir, VA 22060-6218

ATTN: Accessions Division (2)

Director

U.S. Army Materiel Systems Analysis

Activity

392 Hopkins Road

Aberdeen Proving Ground, MD 21005-5071

ATTN: AMXSY-EL

Commander

Chemical/Biological Defense Agency

U.S. Army Armament, Munitions and

Chemical Command

Aberdeen Proving Ground, MD 21010-5423

ATTN: AMSCB-Cil, Library
No. of Copies

Director

U.S. Army Edgewood Research,

Development and Engineering Center

Aberdeen Proving Ground, MD 21010-5423

ATTN: SCBRD-RTB (Aerodynamics

Technology Team)

Director

U.S. Army Research Laboratory

Aberdeen Proving Ground, MD 21005-5066

ATTN: AMSRL-OP-C1-B,

Technical Library

Chief

Benet Weapons Laboratory, CCAC

Armament Research, Development and

Engineering Center

U.S. Army Tank-automotive and

Armaments Command

Watervlet, NY 12189-5000

ATTN: AMSTA-AR-CCB-TL

University of Delaware

Center for Composite Materials

Delaware, DE 19716-3144

ATTN: Dr. J. Gillespie

Commander

U.S. Army Industrial Operations Command

Rock Island, IL 61299-6000

ATTN: AMSIO-IR, R. Janik (4)

\section{Onsite}

\section{(21) Pacific Northwest National Laboratory}

$\begin{array}{ll}\text { K.L. Alford } & \text { K2-44 } \\ \text { G.E. Fryxell } & \text { K2-44 } \\ \text { W.D. Samuels } & \text { K2-44 } \\ \text { K.L. Simmons (10) } & \text { K2-44 } \\ \text { R.D. Voise } & \text { K2-44 } \\ \text { Information Release Office (7) } & \text { K1-06 }\end{array}$

